\title{
MODELING OF PARASITIC DISEASES WITH VECTOR OF TRANSMISSION: TOXOPLASMOSIS AND BABESIOSIS BOVINE
}

\author{
Diego Fernando Aranda Lozano
}

Supervisor

Rafael J. Villanueva Micó

Universidad Politécnica de Valencia

Departamento de Matemática Aplicada 


\title{
MODELING OF PARASITIC DISEASES WITH VECTOR OF TRANSMISSION: TOXOPLASMOSIS AND BABESIOSIS BOVINE
}

\author{
Diego Fernando Aranda Lozano
}

Supervisor

Rafael J. Villanueva Micó

Universidad Politécnica de Valencia

Departamento de Matemática Aplicada 


\section{Content}

List of Figures

$\begin{array}{ll}\text { List of Tables } & \text { IV }\end{array}$

$\begin{array}{lll}\text { Acknowledgements } & \text { VI }\end{array}$

$\begin{array}{lll}\text { Abstract } & \text { VII }\end{array}$

$\begin{array}{lll}\text { Resumen } & \text { IX }\end{array}$

$\begin{array}{lll}\text { Resum } & \text { XI }\end{array}$

1. Introduction 1

1.1. Toxoplasmosis . . . . . . . . . . . . . . . . . . . . . . 1

1.2. Bovine Babesiosis . . . . . . . . . . . . . . . . . . 3

1.3. Epidemiological mathematical models . . . . . . . . . . . . . . . . 4

2. Mathematical Model of Toxoplasmosis Disease in Varying Size Population $\mathbf{5}$

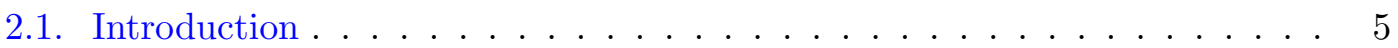

2.2. Mathematical model . . . . . . . . . . . . . . . . 7

2.3. Scaling the model . . . . . . . . . . . . . . . . . . . . 8

2.4. Numerical simulation . . . . . . . . . . . . . . . . . . . . . . 11

2.5. Conclusions . . . . . . . . . . . . . . . . . . . . 14

3. Dynamics of a model of Toxoplasmosis disease in human and cat populations 15

3.1. Introduction . . . . . . . . . . . . . . . . . . . . 15

3.2. Mathematical model . . . . . . . . . . . . . . . . . . . . 18

3.3. Stability analysis of the model . . . . . . . . . . . . . . . . . . . 20

3.3.1. Scaling model . . . . . . . . . . . . . . . . . . . . . . . . . 20

3.3.2. Equilibrium points of the model . . . . . . . . . . . . 21

3.3.3. Stability analysis . . . . . . . . . . . . . . . 22

3.4. Numerical simulations . . . . . . . . . . . . . . . . . . . 25

3.5. Discussion and conclusions . . . . . . . . . . . . . . . . . 27

4. Modeling dynamics of Babesiosis disease in bovines and ticks populations 
4.1. Introduction . . . . . . . . . . . . . . . . . 30

4.2. Mathematical model . . . . . . . . . . . . . . . . . . . . . . . . . . . . . . . . 31

4.3. Analysis of the model . . . . . . . . . . . . . . . . . . . . . . . . . . . . . . . . 34

4.3.1. Model equilibrium points . . . . . . . . . . . . . . 34

4.3.2. Stability analysis . . . . . . . . . . . . . . . . . 35

4.4. Numerical simulations . . . . . . . . . . . . . . . . . . . . . . . . . . . . . . . . . .

4.5. Conclusions . . . . . . . . . . . . . . . . . . . 41

$\begin{array}{ll}\text { Bibliography } & 43\end{array}$ 


\section{List of Figures}

2.1. Diagram of the Toxoplasmosis disease on the population. . . . . . . . . . . . . 8

2.2. Dynamics of the different subpopulations $\beta=0.0206055$ and $\gamma=0.000232$. . . . . . 11

2.3. Dynamics of the different subpopulations $\beta=0.010327$ and $\gamma=0.000232$. . . . . . . 12

2.4. Dynamics of the different subpopulations $\beta=0.0206055$ and $\gamma=0.1$. . . . . . . . 13

3.1. Flow diagram of the Toxoplasmosis disease model for human and cat populations as defined in system (3.1). . . . . . . . . . . . . . . . . 19

3.2. Dynamics of the different subpopulations when $\beta_{c}=0.00066, \gamma=0.000232$ and $\mathcal{R}_{0}=$ 0.909. $\left(X_{1}^{*}=1, Y_{1}^{*}=0\right.$ and $\left.A_{1}^{*}=1\right)$. . . . . . . . . . . . . . . . 26

3.3. Dynamics of the different subpopulations when $\beta_{c}=0.0008, \gamma=0.000232$ and $\mathcal{R}_{0}=$ 1.2121. $\left(X^{*}=0.0603, Y^{*}=0,9386\right.$ and $\left.A^{*}=0.825\right)$. . . . . . . . . . . . 27

3.4. Dynamics of the different subpopulations when $\beta_{c}=0.0008, \gamma=0.000232, p_{c}=0.0001$ and $\mathcal{R}_{0}=121.21$. $\left(X^{*}=0.0112, Y^{*}=0.9878\right.$ and $\left.A^{*}=0.00825\right) \quad \ldots . . . . .27$

4.1. Dynamics of the Babesiosis disease in bovine and tick populations . . . . . . . . . . 33

4.2. Ecologic stability, when $\beta_{B}=0.00061, \beta_{T}=0.00048, \alpha_{B}=0.001$ and $\mathcal{R}_{0}=6.8$. . . . 39

4.3. Dynamics of the different subpopulations when $\beta_{B}=0.0003, \lambda_{B}=0.0265, p=0.1$ and $\mathcal{R}_{0}=0.33 \ldots \ldots$. . . . . . . . . . . . . . . . . . 39

4.4. Dynamics of the different subpopulations when $\beta_{B}=0.006$ and $p=0.1$, with initial condition $S_{B}(0)=0.3816, \quad I_{B}(0)=0.5184, \quad S_{T}(0)=0.60$ and $\mathcal{R}_{0}=67.54$. . . . . 40

4.5. Dynamics of the different subpopulations when $\beta_{B}=0.006$ and $p=0.1$, with initial condition $S_{B}(0)=0.70, \quad I_{B}(0)=0.10, \quad S_{T}(0)=0.20$ and $\mathcal{R}_{0}=67.54$. . . . . . . 40

4.6. The dynamics of the subpopulations is sensitive to the parameters $\beta_{B}$ and $\beta_{T}$. . . . . 41 


\section{List of Tables}

2.1. Basic parameters of the mathematical model . . . . . . . . . . . . . . . 8

2.2. Parameters of the model . . . . . . . . . . . . . . . . . . . 10

2.3. Equilibrium point when $\beta=0.0206055$ and $\gamma=0.000232$ of $\operatorname{system}(2.11)$. . . . . 11

2.4. Eigenvalues of the Jacobian $J\left(s^{*}, e^{*}\right)$ when $\beta=0.0206055$ and $\gamma=0.000232$ of system (2.11) . . . . . . . . . . . . . . . . . . . . 11

2.5. Equilibrium point when $\beta=0.010327$ and $\gamma=0.000232$ of system (2.11) . . . . . . 12

2.6. Eigenvalues of the Jacobian $J\left(s^{*}, e^{*}\right)$ when $\beta=0.010327$ and $\gamma=0.000232$ of system (2.11) 13

2.7. Equilibrium point when $\beta=0.0206055$ and $\gamma=0.1$ of system (2.11) . . . . . . . . 13

2.8. Eigenvalues of the Jacobian $J\left(s^{*}, e^{*}\right)$ when $\beta=0.0206055$ and $\gamma=0.1$ of system (2.11) 14

3.1. Parameters of the model . . . . . . . . . . . . . . . . . . . 26

4.1. Parameters for simulation. The values $\beta_{B}, \beta_{T}$ and $\alpha_{B}$ have been calculated assuming an ecologic stability. . . . . . . . . . . . . . . . . . . 38 


\section{To my parents}

For their unconditional support and excellent work, because their sacrifices are the source of my success.

\section{To my sisters}

For their unconditional support.

And especially to my supervisor Rafael J. Villanueva Micó, without his patience this would not have been possible... . 


\section{Acknowledgements}

To the research group of the Instituto de Matemática Multidisciplinar, by its accompanying and excellence academic; because with they I learned that "A person who never made a mistake, never tried anything new". Albert Einstein.

To Mathematics Department and the Engineering Computer College, from Castilla-La Mancha University, by its scientific support.

To Benjamin Rosenthal Ph.D. of the Agricultural Research Service, USDA by your grammatical review of this research work. 


\section{Abstract}

As the complexity of the world in which we live increases, system thinking is becoming a major factor in success and even in survival. This is why robust tools of complex dynamic systems can give answers to several problems and can be applied to many different areas, such as business, society and ecosystems, as well as in ordinary life such as compulsive shopping, drug abuse, tobacco addiction, obesity, etc. When experiments to test the real world cannot be carried out, simulation becomes the best way to learn about the dynamic of these systems. For this reason I am pleased to present this Ph.D. Dissertation, in which theory and practice of the dynamic systems are combined. It also embraces epidemiologic models of some parasitic diseases with transmission vector.

The Toxoplasmosis and the bovine Babesiosis are parasitic diseases (zoonoses), which are spread through a transmission vector and affect both human beings and livestock. As a public health problem, Toxoplasmosis causes high health care costs when treating unborn and newborn babies. It also causes a great amount of sick leaves. In addition to this, livestock economic sector in tropical countries, such as Colombia, must bear an extra cost of millions of dollars due to the high mortality rates and to the low productivity levels in by-products of farming.

Mathematical models try to describe and represent reality using mathematical techniques. The importance of mathematical modeling when studying the way some diseases can spread lies in forecasting the behaviour of these biological phenomena and their effects wherever they may occur. Thus mathematical models supply a valuable tool for doctors to use for containment methods, estimation and safety, as well as many other different decisions aimed to reduce economic costs.

Three mathematical models, which describe the behaviour of two parasitic diseases with transmission vector, are presented in this dissertation. Two of these models are dedicated to Toxoplasmosis and they explore the dynamic of the disease in relation to human population and pet cats. In this model, cats play the role of infectious agents and carrier of the protozoan Toxoplasma Gondii. The qualitative dynamic of the model is established by the basic reproduction threshold $\mathcal{R}_{0}$. If the parameter $\mathcal{R}_{0}<1$, then the solution converges to the equilibrium point disease free. However, if $\mathcal{R}_{0}>1$, convergence leads to the equilibrium point endemic. Numerical simulations of the models illustrate different dynamics according to the threshold parameter $\mathcal{R}_{0}$ and show the importance of this parameter. Finally, bovine babesiosis is modeled starting from a mathematical model, which is composed of five ordinary differential equations that explain the influence of the epidemiological parameters over the evolution of the disease. The stationary states of the system and the basic reproduction number $\mathcal{R}_{0}$ are determined. The existence of the 
endemic point and the disease free point are calculated and they depend on the threshold parameter $\mathcal{R}_{0}$, which determines the local and global stability of the equilibrium points. 


\section{Resumen}

A medida que la complejidad de nuestro mundo aumenta el pensamiento sistémico se está convirtiendo en un factor crítico para el éxito, e incluso la supervivencia. Es por eso que las herramientas robustas de los sistemas dinámicos complejos pueden dar respuesta a varios problemas, aplicándolas en: Negocios, poblaciones o ecosistemas y en la experiencia cotidiana como: Compras compulsivas, la adicción a las drogas, la adicción al tabaco, obesidad, etc. Cuando los experimentos en el mundo real son imposibles, la simulación se convierte en la principal forma de que podamos aprender de manera efectiva sobre la dinámica de dichos sistemas. Por esta razón me complace presentar esta Tesis, donde se combina la teoría y la práctica de los sistemas dinámicos, abarcando a modelos epidemiológicos de algunas enfermedades parasitarias con vector de transmisión.

La Toxoplasmosis y la Babesiosis bovina son enfermedades parasitarias (Zoonosis) que se transmiten a través de un vector transmisor afectando a la población de humanos y al sector ganadero respectivamente. Como problema de salud pública la Toxoplasmosis genera altos costes de atención en salud prenatal y natal sin mencionar la perdida de días laborales; de igual manera la Babesiosis bovina le cuesta miles de millones de dólares al sector ganadero en países tropicales como Colombia por la mortalidad bovina y baja productividad de los derivados.

Los modelos matemáticos pretenden mitigar, copiar, describir o representar la realidad mediante el uso de técnicas matemáticas. La importancia de la modelización matemática de la propagación de enfermedades radica en la predicción del comportamiento de dichos fenómenos biológicos y sus efectos en el entorno donde suceden, proporcionando una valiosa herramienta en los métodos de contención, estimación y seguridad para el personal médico y en otras múltiples decisiones encaminadas a la minimización de costes económicos.

En esta tesis doctoral se presentan tres modelos matemáticos que describen el comportamiento de dos enfermedades parasitarias con vector de transmisión; de los cuales dos modelos están dedicados a la Toxoplasmosis donde se explora la dinámica de la enfermedad a nivel de la población humana y de gatos domésticos. Los gatos en este modelo juegan un papel de agentes infecciosos y conductores del protozoo Toxoplasma gondii. La dinámica cualitativa del modelo es determinada por el umbral básico de reproducción, $\mathcal{R}_{0}$. Si el parámetro $\mathcal{R}_{0}<1$, entonces la solución converge al punto de equilibrio libre de la enfermedad. Por otro lado, si $\mathcal{R}_{0}>1$, la convergencia es al punto de equilibrio endémico. Las simulaciones numéricas de los modelos ilustran diferentes dinámicas en función del parámetro umbral $\mathcal{R}_{0}$ y muestra la importancia de este parámetro. Y finalmente la Babesiosis bovina se modela a partir de un modelo matemático constituido por cinco 
ecuaciones diferenciales ordinarias, que permiten explicar la influencia de los parámetros epidemiológicos en la evolución de la enfermedad. Los estados estacionarios del sistema y el número básico de reproducción $\mathcal{R}_{0}$ son determinados. La existencia de los puntos de equilibrio endémico y libre de enfermedad son calculados, los cuales depende del valor del parámetro umbral $\mathcal{R}_{0}$ y determina la estabilidad local y global de dichos puntos. 


\section{Resum}

A mesura que la complexitat del nostre món augmenta, el pensament sistèmic està convertint-se en un factor crìtic per al éxit i inclós, la supervivencia. És per això que que les ferramentes robustes dels sistemes dinàmics complexos poden donar resposta a varios problemes aplicant-les en negocis, poblacions o ecosistemes i en la experiència quotidiana com les compres compulsives, adicció a les drogues i al tabac, obesitat, etc. Quant els experiments al món reial són impossibles, la simul.lació es convertix en la principal forma de que puguem ensenyarmos de manera efectiva sobre la dinámica dels estos sistemes. Per eixa raó em complau presentar esta Tesi, on es combina la teoría i la pràctica dels sistemes dinàmics, abarcant models epidemiològics de algunes enfermetats parasitàries amb vector de transmissió.

La Toxoplasmosi i la Babasiosi bovina son enfermetats parasitàries (Zoonosi) que es transmiteixen a través d'un vector transmisor afectant a poblacó d'humans i al sector ramader. Com a problema de salut pública, la Toxoplasmosi genera alts costos d'atenció en salut prenatal i natal, sense mencionar la pèrdua de diez de treball; de igual forma la Babesiosi bovina costa milers de milions de dolars al sector ramader en països tropicals com Colómbia per la mortalitat bovina i la baixa productivitat dels derivats. Els model matemàtics permitixen descriure i representar la realitat mitjantant l'us de tècniques matemàtiques. La impotància de la modelització matemática de la propagació d'enfermetats radica en la predicció del comportament d'eixos fenómens biològics i els seus efectes en el entorn on succeixen, proporcionant una valuosa ferramenta en els métodes de contenció, etimació i seguretat per al personal metge i en altres múltiples decisions encaminades a la minimització dels costos económics.

En esta tesi doctoral es presenten tres models matemàtics que descriuen el comportament de dues enfermetats parasitàries amb vector de transmissió. Dos d'ells están dedicats a la Toxoplasmosi, on s'explora la dinámica de l'enfermetat a nivel de la población humana i dels gats domèstics. Els gats en este model juguen el paper d'agents infecciosos i conductors del protozoo Toxoplasma Gondii. La dinámica qualitativa del model es determinada per l'umbral bàsic de reproducció $\mathcal{R}_{0}$. Si el paràmetre $\mathcal{R}_{0}<1$, entonces la solución convergix al punt d'equilibri lliure d'enfermetat. Per altra part, si $\mathcal{R}_{0}>1$ la convergencia és al punt d'equilibri endèmic. Les simulacions numèriques dels modelos il.lustren diferents dinàmiques en funció del paràmetre umbral $\mathcal{R}_{0}$ i mostra la importància d'este paràmetre. I finalment la Babesiosi bovina es model.la a partir d'un model matemàtic format per cinc equacions diferencials ordinàries, que permiteixen explica l'influència dels paràmetres epidemiològics en l'evolució de l'enfermetat. Es determinen els estats estacionaris dels sistemes i el número básic de reproducció $\mathcal{R}_{0}$. La existencia dels punts 
de equilibri endèmic i lliure d'enfermetat es calculen i depenen del paràmetre umbral $\mathcal{R}_{0}$, que determina l'estabilitat local i global dels punts d'equilibri. 


\section{Chapter 1}

\section{Introduction}

Parasitic diseases have been linked to the history of mankind and can be found in both animals or plants. Some parasites have been found in fossils of foraminifera (Protozoa) which are more than 530 million years old. The origin of parasites in humans comes from ancient times and has been defined by different cultures as Greek, Egyptian and Chinese [12]. Then we may say that the parasites have coexisted with humanity and the diseases produced by them affect the health and economy of regions [55]. This is especially noticeable, in tropical countries, where the spread among humans and their livestock is becoming a public health problem with high rates of morbidity and mortality because of the poor social and economic conditions of most of the people in these countries [12].

Different parasitic diseases have existed. Some of them are important problems because of the difficulty to control them: Malaria, Esquistosomiasis, Leishmaniasis, Chagas's disease, Toxoplasmosis, Babesiosis and the intestinal parasitosis are some examples [48]. Parasitic diseases constitute a problem in Colombia and are common in all the population. The most vulnerable population are the to-be-borns and newborns [56, 61].

\subsection{Toxoplasmosis}

The etiological agent of Toxoplasmosis is Toxoplasma gondii, which is a protozoan of the order Eucoccidiorida and family Sarcocystidae, characterized as an intracellular parasite that lives in the host cell by regulating vital processes to acquire nutrients, guaranteeing its survival and thus evading the host immune system [36]. It is common in warm-blooded vertebrate animals in the world [31], including humans [36], and it is transmitted through food chains, mainly through carnivores and scavengers [11]. 
This parasite has a life cycle divided into three stages: The first is oocyst, when the parasite can survive for long periods of time outside the host due to its high resistance to environmental factors [34]; In the second, called bradyzoite, the latent form of the parasite (chronic) is present in microscopic conglomerates and is found in infected muscle and brain tissues [39]; And the third, tachyzoite, is a rapid multiplying stage in the development of the tissue phase in acute infections of Toxoplasmosis, when cysts in tissues infected by toxoplasma are formed by tachyzoites found in vacuoles within infected cells [17].

Cats and some felines are the definitive hosts of T. gondii [38]. It can develop its life cycle in the intestinal epithelium of these animal $[36,49]$. Once infected cats excrete their wastes (oocysts) to the environment, it may infect any vertebrate animal that consumes the oocysts, including humans [12]. Ingestion and manipulation of raw or undercooked meat, unwashed vegetables and fruits, the consumption of the unboiled water and contact with cats are risk factors that increase the likelihood of ingesting oocysts and consequently the development of Toxoplasmosis [37]. In humans, if the infection happens during the stage of pregnancy, the Toxoplasma gondii can be transmitted vertically to the fetus through the tachyzoites [40], invade the cells and infect all the organs of the fetus [58], primarily retina, brain, muscle, heart, lung, etc., and thus cause congenital Toxoplasmosis [53].

Congenital Toxoplasmosis [36] leaves irreversible sequelae in the infant at birth, such as epilepsy, mental retardation, retinochoroiditis, macrocephaly, microcephaly, developmental delay microphthalmia, strabismus and retinochoroiditis plates [12]. The disease may be present in latent form, manifesting itself years later [53]. Toxoplasmosis can be remarkably aggressive if it affects patients with AIDS, transplant, in steroid or antineoplastic therapy [27].

In the United States, Toxoplasma gondii the third most common cause of transmission by oral ingestion. Health authorities, report 225000 cases of infection by Toxoplasma gondii per year; caused 5000 hospitalizations and 750 deaths [41]. In Europe there is variation in the sero-prevalence among pregnant women: in France it is around $54 \%$, while in Sweden is $12 \%$ [2]. In Latin America, Mexico has a prevalence of $35 \%$ [2] and in Brazil (Sao Paulo, Rio de Janeiro) reported different values, have been reported between $59 \%$ and $78 \%$ [7].

In a study done between 1977 and 1980 in Colombia [26], the seroprevalence rate ranged between $42.5 \%$ and $54.4 \%$ in women of childbearing age. The prevalence was determined by antibody detection techniques (IgG, $\operatorname{IgM}$ and $\operatorname{Ig} A)[28,42]$. This study estimated that between 2 and 10 live newborns have Toxoplasmosis out of every 1000 births in Colombia, i.e., between 600 and 3000 children out of 300000 new live births per year would be born 
with the congenital infection, most of them totally asymptomatic (450-2250), only 150750 would display symptoms in the first months of life [28].

\subsection{Bovine Babesiosis}

The etiological agent of the Bovine Babesiosis and Babesia Bigemina is the Babesia Bovis, which is an hemoparasite of order Piroplasm and family Babesiidae, discovered in 1888 by Romanian biologist Victor Babes [6]. The first case documented in humans occurred in 1957 in the former Yugoslavia [21]. Between 1982 and 2001 there were 200 reported cases in the EE.UU [21].

This disease takes on importance in the livestock sector due to the high economic impact, especially in tropical regions. In Colombia there is an economic loss due to the high bovine death, limiting the productivity increase of bovine derivatives and affecting the Gross Domestic Product (GDP) [9].

The bovine babesiosis is a typical disease that is transmitted through the tick (transmission vector) [62]. A bovine could be infected through a sting and if it is pregnant, it is possible a vertical transmission [51]. Furthermore, the vector could be infected if it has a direct contact with a bovine infected and vertical transmission is a fact $[62,64]$. The parasite has a life cycle in the ticks: When a tick bites an infected cow, the gametes fuse in the gut of the tick, resulting in a zygote; Zygotes become in mobile ookinete, entering the salivary glands of the tick, then a cycle of sporogony starts, resulting in new sporozoites, which can be re-injected into a bovine through a tick bite [62].

Thus, the parasite life cycle in the bovine begins when the sporozoites enter into the blood of the bovine by the bite of an infected tick. This initial stage of sexual reproduction may cause infection in the bovine $[6,62]$. Some of the most critical pathologies in bovine are the acute anemia due to destruction of red blood cells and dehydration caused by the vomiting due to retention of bile in the animal [13].

In the tropics zones there are approximately 1.3 billion of cattle at risk due to Babesiosis [62] which may cause an economic bankruptcy for the livestock sector all over the world. A study conducted in Colombia, in which 2909 blood samples of bovine from 104 farms were analyzed, showed a prevalence of $4.1 \%$ [20]. The detection techniques used were real-time PCR [47]. 


\subsection{Epidemiological mathematical models}

Mathematical models in epidemiology have been used since 1760, when Daniel Bernoulli published a treatise on the smallpox epidemic [1]. In 1906 Hamer presented a discrete model for mumps; shortly after Ronald Ross, in the edition of 1911 of his book The Prevention of Malaria, formulated a simple mathematical model; According to Ross' model, the eradication of malaria would be achieved by decreasing the population of mosquitoes, whose extinction would not be essential [57]. Later in 1927, Kermack and McKendrick formulated a mathematical model to describe the bubonic epidemic of plague in India in 1906 [3].

Mathematical models are helpful in different areas. One of them is epidemiology, which has become an important tool used in the analysis and control of infectious diseases. A classical technique to model diseases in the population is the use of systems of ordinary differential equations describing the evolution of the number of individuals in different subpopulations. In particular, mathematical models using first order nonlinear differential equations for parasitic diseases with vector of transmission have been presented in $[4,5,22,23]$. In these articles, the authors model the spread of parasitic diseases, calculate the basic reproduction threshold $\mathcal{R}_{0}$ [46], estimate some unknown parameters, carry out numerical simulations using Matlab packages with private data and study the behaviour of analytical solutions.

The field of nonlinear dynamical systems provides powerful tools to analyze the dynamic behaviour of diseases. The study of the eigenvalues of Jacobian associated to the linearized system leads to the identification of local stability. Sometimes it is possible to demonstrate the global stability using the Lyapunov function [5, 22].

Using the above tools, we tackle this research in the epidemiological mathematical modeling in parasitic diseases such as Toxoplasmosis and Bovine Babesiosis in order to understand their spread and epidemiological behaviour over time and predict their impact. 


\section{Chapter 2}

\section{Mathematical Model of Toxoplasmosis Disease in Varying Size Population}

The prevalence of Toxoplasmosis has increased dramatically around the world. Despite the fact that congenital Toxoplasmosis cannot be considered a disease of epidemic proportions, it may cause either death in humans or serious effects in developing fetus. In this chapter we present an initial model with varying population size for the evolution of the infected people with Toxoplasmosis. We explore the dynamics of the Toxoplasmosis disease at population level by using an epidemiological model. Statistical data are used to estimate some of the parameters of the model. Numerical simulations of the model, which have been carried out by varying parameters, show different scenarios of the spread of the disease.

\subsection{Introduction}

The protozoan Toxoplasma Gondii is a prevalent parasite in wild and domestic animals worldwide, transmitted through the food chain by carnivorous feeding and scavenging. Toxoplasma normally divides asexually to yield a haploid form that can infect virtually any vertebrate, but also has a well-defined sexual cycle that occurs exclusively in cats. If the first contact happens during pregnancy, Toxoplasma Gondii can be transmitted vertically by tachyzoites, which are passed to the fetus via the placenta [59]. 
The Toxoplasma Gondii has become important as an opportunist pathogen in patients with AIDS, although the $15 \%-85 \%$ of the adult human population that is chronically infected with T. gondii is typically asymptomatic [59]. Infections in immunocompromised hosts have variable outcomes. In the USA, recent outbreaks of acute Toxoplasmosis in humans have been associated with oocyst contamination of the environment [59]. Over the course of recent history, humans have domesticated many different animal species, but the principal ones have been dogs, domesticated 12000 years ago, and cats, domesticated 4000 years ago. However, from these modest and comparatively recent beginnings, the cat is now on the verge of becoming the Western world's most popular pet. Current predictions state that cats will soon overtake dogs as the most commonly kept pet. According to the Pet Food Institute in Washington, DC, cats already outnumber dogs in the United States, with 70.2 million, and in Spain with 5.5 million of cats [65].

In the United States there are approximately 225,000 cases of Toxoplasma Gondii infection per year. This results in 5000 hospitalizations and 750 deaths, making Toxoplasma gondii the third most common cause of fatality. Since more than $90 \%$ of primary Toxoplasmosis infections in immunocompetent persons are asymptomatic, the diagnosis of maternal infection can be difficult. In asymptomatic women, the only sign of primary infection during pregnancy is seroconversion via detection of $\operatorname{IgG}$ or $\operatorname{IgM}$ by the immunofluorescence antibody test, the enzyme-linked immune filtration assay, the immunosorbent agglutination assay (ISAGA), or other similar assays. IgG antibody levels become detectable 1-2 weeks after infection and remain elevated indefinitely, while IgM antibody levels increase within days and usually remain elevated during 2-3 months. However, up to $27 \%$ of women have IgM antibodies during more than 2 years, making difficult to pinpoint the timing of infection. Thus, the detection of IgG in a woman at the beginning of pregnancy indicates prior infection and eliminates the risk of congenital transfer of tachyzoi [41].

In Colombia, in accordance with the National Research of Health, $47 \%$ of the human population have antibody vs Toxoplasma it shows that people have contact with protozoan during their life goes unnoticed in people with an excellent immune system [28]. The most important health consequences affect newborns with the infection acquired in uterus and immune deficiency in patients with AIDS. It is estimated that between 2 and 10 newborns have Toxoplasmosis out of 1000 births in Colombia. Therefore, between 600 and 3000 children of the 300,000 new births per year, would be born with the congenital infection, most of them totally asymptomatic (450-2250), while only 150-750 would display symptoms in the first months of life [28].

We should mention that, as far as we know, this is the first mathematical model of the evolution of Toxoplasmosis in the human population. 
In this chapter a first approach to model the evolution of the Toxoplasmosis disease in human population is introduced using a SIC model (susceptible-infected-controlled). In Section 2.2, we present the mathematical model for the evolution of Toxoplasmosis. Section 2.3 , is devoted to scale the model properly to match with available data. In Section 2.4, mathematical simulations for three different scenarios are performed. Finally in Section 2.5, conclusions are presented.

\subsection{Mathematical model}

In this section a first mathematical model for the evolution of the Toxoplasmosis in the population is formulated. Following the basic ideas and structure of mathematical modeling in epidemiology, the model for the Toxoplasmosis disease will be developed under the next basic hypotheses $[14,29,46]$.

1. The total population $N(t)$ is divided into three subpopulations:

- Susceptible $S(t)$ : members of the population who may become infected.

- Infected $E(t)$ : members of population infected by the Toxoplasmosis parasite, both asymptomatic and symptomatic.

- Controlled $C(t)$ : members of the population who have been treated for the Toxoplasmosis.

2. A susceptible individual transits at a rate $\beta$ to the infected subpopulation $I(t)$. An infected person transits to the controlled subpopulation $C(t)$ at a rate $\gamma$.

3. The birth rate $\mu$ is assumed time-independent as well as the natural death rate $d$. The transmission rate $\beta$ is assumed to be dependent on the population of cats, the accumulation of oocyst in the environment and the population of other animals (birds, rats and mice), but also time-independent. A newborn has a probability $p$ to be healthy, i.e., to be born without Toxoplasmosis. The additional death rate caused by Toxoplasmosis is $\varepsilon$.

4. All members of the susceptible subpopulation $S(t)$ have the same probability to be infected [14].

A summary of the description of parameters is presented in Table 2.1 


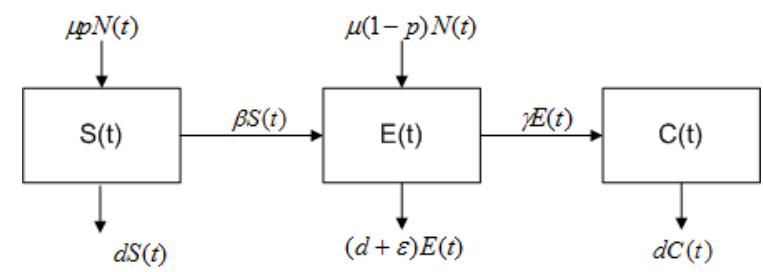

FiguRE 2.1: Diagram of the Toxoplasmosis disease on the population.

\begin{tabular}{lr}
\hline Parameter & Description \\
\hline$\gamma$ & Individuals with Toxoplasma controlled rate \\
$p$ & Probability to be born without Toxoplasma \\
$\varepsilon$ & Death rate caused by Toxoplasma \\
$d$ & Natural death rate \\
$\beta$ & Transmission rate \\
$\mu$ & Birth rate \\
\hline
\end{tabular}

TABLE 2.1: Basic parameters of the mathematical model

Under the above assumptions, an epidemiological model for Toxoplasmosis is given by the following linear system of ordinary differential equations.

$$
\begin{aligned}
\dot{S}(t) & =p \mu N(t)-d S(t)-\beta S(t) \\
\dot{E}(t) & =\beta S(t)+\mu(1-p) N(t)-(d+\varepsilon) E(t)-\gamma E(t), \\
\dot{C}(t) & =\gamma E(t)-d C(t) \\
N(t) & =S(t)+E(t)+C(t)
\end{aligned}
$$

where $S(t), E(t)$ and $C(t)$ represent the number of individuals in the three subpopulations at time $t$. The schematic representation of the flow of individuals between the different subpopulations is shown in Figure 2.1. This model is used to estimate some unknown parameters related to Toxoplasmosis. Numerical simulations are carried out to analyse the effect of different control measures against the disease.

\subsection{Scaling the model}

Since data available are in percentages, and the model in Eq. (2.1) is referred to number of individuals, it leads us to scale the model into the same units as data. Therefore, following ideas developed in papers $[15,44]$ about how to scale models with populations 
varying in size, adding the first three equation of the system (2.1) and using the last one, we obtain that,

$$
\dot{N}(t)=(\mu-d) N(t)-\varepsilon E(t)
$$

Dividing both members of $(2.2)$ by $N(t)$ one gets

$$
\frac{\dot{N}(t)}{N(t)}=\mu-d-\varepsilon \frac{E(t)}{N(t)}
$$

If we define the ratios (dependent on time)

$$
s(t)=\frac{S(t)}{N(t)}, \quad e(t)=\frac{E(t)}{N(t)}, \quad c(t)=\frac{C(t)}{N(t)}
$$

the Eq. (2.3) can be transformed into

$$
\frac{\dot{N}(t)}{N(t)}=\mu-d-\varepsilon e(t)
$$

Now, let us calculate the derivative of $s$ using (2.5). Then, we obtain that

$$
\dot{s}(t)=\frac{\dot{S}(t) N(t)-S(t) \dot{N}(t)}{N^{2}(t)}=\frac{\dot{S}(t)}{N(t)}-\frac{S(t)}{N(t)} \frac{\dot{N}(t)}{N(t)}=\frac{\dot{S}(t)}{N(t)}-s(t)(\mu-d-\varepsilon e(t)),
$$

and analogously, one gets that,

$$
\dot{e}(t)=\frac{\dot{E}(t)}{N(t)}-e(t)(\mu-d-\varepsilon e(t)), \quad \dot{c}(t)=\frac{\dot{C}(t)}{N(t)}-c(t)(\mu-d-\varepsilon e(t)) .
$$

Now, let us consider the first equation of system (2.1). If we divide by $N(t)$, we have

$$
\frac{\dot{S}(t)}{N(t)}=p \mu-d \frac{S(t)}{N(t)}-\beta \frac{S(t)}{N(t)}
$$

and substituting by the corresponding ratios defined in (2.4) and using (2.8) we obtain the scaled equation. 


$$
\dot{s}(t)=p \mu-s(t)(\mu+\beta-\varepsilon e(t)) .
$$

Remaining parts of the system (2.1) can be scaled similarly to obtain

$$
\begin{aligned}
\dot{e}(t) & =\beta s(t)+\mu(1-p)-(\gamma+\mu+\varepsilon-\varepsilon e(t)) e(t), \\
\dot{c}(t) & =\gamma e(t)-(\mu-\varepsilon e(t)) c(t), \\
1 & =s(t)+e(t)+c(t) .
\end{aligned}
$$

Notice that, after scaling the model, it has been transformed into a nonlinear one. As $1=s(t)+e(t)+c(t)$ we can eliminate $c(t)$ and consider the two-dimensional system

$$
\begin{aligned}
& \dot{s}(t)=p \mu-s(t)(\mu+\beta-\varepsilon e(t)), \\
& \dot{e}(t)=\beta s(t)+\mu(1-p)-(\gamma+\mu+\varepsilon-\varepsilon e(t)) e(t) .
\end{aligned}
$$

\begin{tabular}{lr}
\hline Parameter & Values \\
\hline$p$ & 0.9898 \\
$\varepsilon$ & $5.08 \times 10^{-6}$ \\
$d$ & 0.00601 \\
$\mu$ & 0.233 \\
\hline
\end{tabular}

TABLE 2.2: Parameters of the model

Some of the model parameters can be estimated and summarized in Table 2.2 from the following sources:

- Between 2-10 out of 1000 newborns in Colombia have Toxoplasmosis [28].

- In the United States there are 225,000 cases of Toxoplasmosis per year and 750 deaths caused by the parasite [41].

- National statistics from Colombia [45].

The parameters $\beta$ and $\gamma$ are unknown and we vary them in the next section to simulate different scenarios. 


\subsection{Numerical simulation}

In this section, we simulate three possible scenarios and observe the effects of the parameters $\beta$ and $\gamma$ on the transmission dynamics of the Toxoplasmosis disease. Taking into account that in Colombia approximately $47.74 \%$ of the population have antibodies against the Toxoplasma Gondii [28], we assume as initial condition in all scenarios the following values

$$
s(0)=0.5253 \quad e(0)=0.47 \quad c(0)=0.0047 .
$$

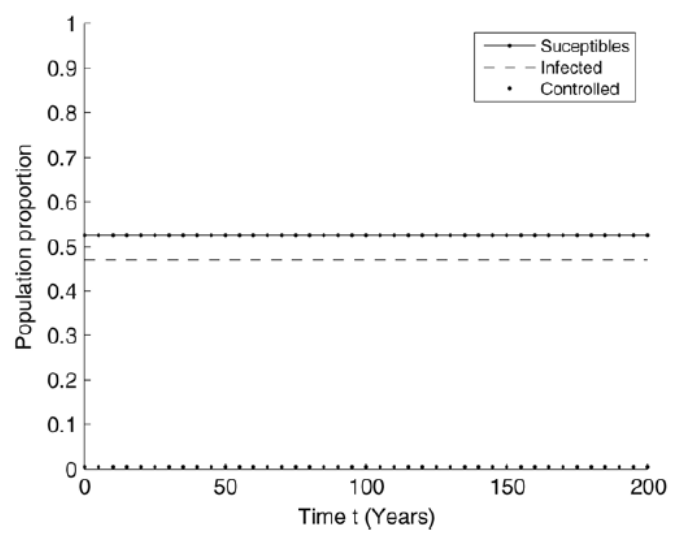

FiguRE 2.2: Dynamics of the different subpopulations $\beta=0.0206055$ and $\gamma=0.000232$.

\begin{tabular}{lr}
\hline Equilibrium point & Values \\
\hline$s^{*}$ & 0.5253 \\
$e^{*}$ & 0.47 \\
$c^{*}$ & 0.0047 \\
\hline
\end{tabular}

TABLE 2.3: Equilibrium point when $\beta=0.0206055$ and $\gamma=0.000232$ of system $(2.11)$

\begin{tabular}{lr}
\hline Eigenvalues & Values \\
\hline$\lambda_{1}$ & -0.0439 \\
$\lambda_{2}$ & -0.0235 \\
\hline
\end{tabular}

TABLE 2.4: Eigenvalues of the Jacobian $J\left(s^{*}, e^{*}\right)$ when $\beta=0.0206055$ and $\gamma=0.000232$ of system (2.11) 
For the first simulation we consider that the spread of Toxoplasmosis in the population of Colombia is in equilibrium, i.e., proportions of susceptible infected and controlled are invariant over time. This fact is possible by taking the parameter values

$$
\beta=0.0206055 \quad \gamma=0.000232 .
$$

Thus, we can compute the equilibrium point $\left(s^{*}, e^{*}\right)$ and the jacobian $J\left(s^{*}, e^{*}\right)$ of system (2.11). The eigenvalues of $J\left(s^{*}, e^{*}\right)$ are negative and therefore the equilibrium point $\left(s^{*}, e^{*}\right)$ is locally asymptotically stable [30] See Tables 2.3 and 2.4. In Fig. 2.1 it can be seen that the solutions $s(t), e(t)$ and $c(t)$ remain invariant over time.

In the second simulation the transmission rate $\beta$ is reduced to the half value of the previous simulation i.e. $\beta=0.0103027$. This assumption considers a situation where health institutions of Colombia take hygienic actions against the oocyst in the environment and create health education programs. The value of $\gamma$ is maintained at the same value as the first simulation. In Tables 2.5 and 2.6, the equilibrium point $J\left(s^{*}, e^{*}\right)$ is shown.

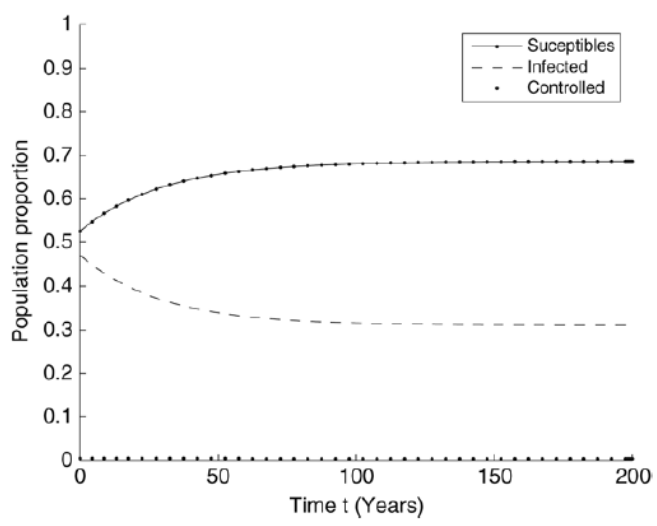

FiguRE 2.3: Dynamics of the different subpopulations $\beta=0.010327$ and $\gamma=0.000232$.

\begin{tabular}{lr}
\hline Equilibrium point & Values \\
\hline$s^{*}$ & 0.6863 \\
$e^{*}$ & 0.3105 \\
$c^{*}$ & 0.003092 \\
\hline
\end{tabular}

TABLE 2.5: Equilibrium point when $\beta=0.010327$ and $\gamma=0.000232$ of system (2.11)

The obtained eigenvalues are negative, therefore the equilibrium point is locally asymptotically stable. In addition, Fig. 2.3 shows that the solutions $s(t), e(t)$ and $c(t)$ converge to the equilibrium point, despite initial condition being far from the equilibrium point 


\begin{tabular}{lr}
\hline Eigenvalues & Values \\
\hline$\lambda_{1}$ & -0.0336 \\
$\lambda_{2}$ & -0.0235 \\
\hline
\end{tabular}

TABLE 2.6: Eigenvalues of the Jacobian $J\left(s^{*}, e^{*}\right)$ when $\beta=0.010327$ and $\gamma=0.000232$ of system (2.11)

$\left(s^{*}, e^{*}, c^{*}\right)$. The effectiveness of the hygienic actions have been achieved since the infected population decreased (see Fig. 2.3).

Finally, for the third simulation, we consider a scenario where the health institutions take more control on the infected people, doing more tests for seropositive Toxoplasmosis and giving more treatment for seropositive individuals. In Tables 2.7 and 2.8, the equilibrium point $\left(s^{*}, e^{*}, c^{*}\right)$ and the eigenvalues of the Jacobian $J\left(s^{*}, e^{*}\right)$ are shown. The obtained eigenvalues are negative, therefore the equilibrium point is locally asymptotically stable. Additionally in Fig. 4 it is possible to see that the solutions $s(t), e(t)$ and $c(t)$ converge to the equilibrium point, despite the fact that the initial condition is far from the equilibrium point $\left(s^{*}, e^{*}, c^{*}\right)$. Since infected population decreases we conclude that extreme preventive measures are good options to control the disease.

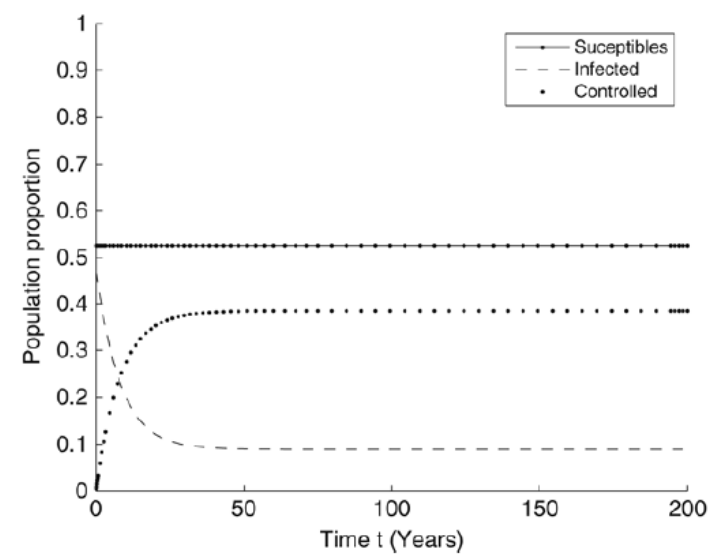

FiguRE 2.4: Dynamics of the different subpopulations $\beta=0.0206055$ and $\gamma=0.1$.

\begin{tabular}{lr}
\hline Equilibrium point & Values \\
\hline$s^{*}$ & 0.5252 \\
$e^{*}$ & 0.08970 \\
$c^{*}$ & 0.3851 \\
\hline
\end{tabular}

TABLE 2.7: Equilibrium point when $\beta=0.0206055$ and $\gamma=0.1$ of system $(2.11)$ 


\begin{tabular}{lr}
\hline Eigenvalues & Values \\
\hline$\lambda_{1}$ & -0.1233 \\
$\lambda_{2}$ & -0.04390 \\
\hline
\end{tabular}

TABLE 2.8: Eigenvalues of the Jacobian $J\left(s^{*}, e^{*}\right)$ when $\beta=0.0206055$ and $\gamma=0.1$ of system

$(2.11)$

\subsection{Conclusions}

In this chapter, we propose a simple mathematical model to study the dynamics of Toxoplasmosis disease in the population of Colombia. The model divides the total population into three subpopulations: susceptible, infected and controlled. The initial model is constructed using a linear system of ODEs, but since in the model size populations are varying and data are in percentages, the model is transformed into relative values in order to observe the qualitative behaviour. The transformed model is a nonlinear system of ODEs where it is possible to do a better analysis of the transmission dynamics of the Toxoplasmosis disease. Afterwards, three numerical simulations are performed in different scenarios, which are based on some situations that could happen in real life. In the last two scenarios it is possible to see the effect of some strategies for the control of Toxoplasmosis, such as hygienic actions, educations programs, more testing and treatments. Finally it should be mentioned that, as far as we know, this is the first mathematical model for the evolution of Toxoplasmosis disease in the human population.

This work has been published in Computers and Mathematics with Applications 56 (2008) $690-696$. 


\section{Chapter 3}

\section{Dynamics of a model of Toxoplasmosis disease in human and cat populations}

A mathematical model for the transmission of Toxoplasmosis disease in human and cat populations is proposed and analyzed. We explore the dynamics of the Toxoplasmosis disease at the population level using a type-epidemiological model. Discussion of the basic concepts of Toxoplasmosis transmission dynamics on human and cat populations are presented. The cats in this model play the role of infectious agents and host of the protozoan Toxoplasma Gondii parasite. Qualitative dynamics of the model are determined by the basic reproduction number, $\mathcal{R}_{0}$. If the threshold parameter $\mathcal{R}_{0}<1$, then the solution converges to the disease free equilibrium point. However, if $\mathcal{R}_{0}>1$ the convergence is to the endemic equilibrium point. Model numerical simulations illustrate different dynamics depending on the threshold parameter $\mathcal{R}_{0}$ and show the importance of this parameter.

\subsection{Introduction}

The protozoan Toxoplasma Gondii is a prevalent parasite in wild and domestic animals worldwide. The life cycle of Toxoplasma is unusual, because this organism is capable of indefinite replication using either sexual or asexual subcycles.

The asexual cycle is of special interest because it may occur in any warm-blooded animal, especially in cats [50] and humans. The cats are considered immune to toxoplasma and it can cast more than 20 million oocysts between 4 and 13 days after the infection and 
these may infect humans [35]. The asexual portion of its life cycle consists of just two stages, the faster division of tachyzoites and the slower division of bradyzoites. The bradyzoites may encyst in the brain, heart and other tissues. Theoretically, this asexual life cycle could continue indefinitely, cycling around the food chain [10].

Transmission occurs when an animal ingests bradyzoite infected tissue through meat or vegetables $[8,10]$. It can also occur accidentally through contaminated food with animal parts. In particular, vertical transmission is possible when tachyzoites enter into the fetus via the placenta [58].

Throughout history, humans have domesticated different animals, mainly dogs and cats, 12,000 and 4000 years ago, respectively. However, the cat is now on the verge of becoming the western world's most popular pet. Current predictions state that cats will soon overtake dogs as the most commonly kept pet. According to the Pet Food Institute in Washington, DC, cats already outnumber dogs in the United States, with 70.2 million, in Spain with 5.5 million cats [65] in Colombia $10 \%$ of households have a cat as pet [70].

The cat is considered a transmission vector of the Toxoplasmosis disease, as it is considered the A. aegypti to dengue disease [22]. Moreover, in some small islands where there are different kind of animals but not cats, the prevalence of Toxoplasmosis is null [8].

The oocysts released in the feces of infected cats contaminate the environment, including vegetables and other kind of food. Therefore, the Toxoplasma gondii can be acquired through ingestion. This type of transmission has been considered the main source of infection in tropical countries [25]. The prevalence of the Toxoplasma gondii antibody in some animals ranges from $12 \%$ to $60 \%$ and in pigs goes from $26 \%$ to $78 \%$. These ranges show the variability in different Latin American countries, such as Argentina, Brazil and Colombia [32, 33]. Toxoplasma infection can be transmitted to humans either by ingestion of tissue cysts in meat or by ingestion of oocysts in cat feces. Some researchers have reported an increasing prevalence of infection of Toxoplasma gondii in the human population [54]. Therefore, based on all the aforementioned facts, it is important to construct models to study and prevent Toxoplasmosis disease.

Mathematical models, simpler than the reality, allow us to understand the global dynamical behaviour of Toxoplasmosis disease in human and cat populations. An important issue that is addressed here is the impact of the epidemics on the human population taking the cat population as a transmission vector. In order to explore the dynamics of the Toxoplasmosis disease in both populations, humans and cats, a type-epidemiological model is used. A system of nonlinear differential equations to study the dynamics of the human and cat infected populations is developed. This modeling approach is a standard way to investigate the dynamics of diseases in populations from a epidemiological 
point of view $[14,46]$. The proposed system consists of modeling the interactions among susceptible and infective individuals of the two species, assuming that the horizontal transmission of the disease to humans happens only through the contact with infected cats and vertical transmission in both cat and human populations. In the model, human population is divided into three classes or subpopulations, susceptibles $S_{h}(t)$, infectious $I_{h}(t)$ and controlled $C_{h}(t)$ and the cat population into two classes, susceptibles $S_{c}(t)$ and infectious $I_{c}(t)$.

The model is described by a system of nonlinear ordinary differential equations with five equations, which allow us to discuss how the different epidemiological parameters influence global behaviour in the evolution of Toxoplasmosis disease in human and cat populations. The model includes the interactions among susceptible and infective individuals of the two species assuming that the horizontal transmission of the disease to humans takes place through the contact with infected cats. This transmission is modeled with a classical incidence rate, however it also may be modeled using another incidence rate such a polynomial one $[29,66]$. Additionally, vertical transmission in both cat and human populations is considered. In human population vertical transmission is assumed with probability 1 . In the cat population, it is assumed that a cat borne from a infected one has a probability $p_{c}$ of not being infected. Furthermore, we assume that both populations of cats and human are constant. This fact is reasonable in some environments where births are approximately balanced by the natural deaths and for short time horizons. In [43] a computer simulation of the transmission of Toxoplasma Gondii is developed considering equilibrium in the cat population size.

In this chapter we study the stability of the steady states of the system and we find that the basic reproductive number $\mathcal{R}_{0}$ controls completely the dynamics of the infection. This basic reproductive number should be regarded as a measure of the capacity of the cats to transmit Toxoplasmosis. We prove that the basic reproduction number $\mathcal{R}_{0}$ is a threshold value that completely determines the global dynamics and the outcome of the disease. If the threshold parameter $\mathcal{R}_{0}<1$, then the solution converges to the disease free equilibrium point. Also, if $\mathcal{R}_{0}>1$ the solution tends to the endemic equilibrium point. Numerical simulations of the model illustrate several different dynamics depending on the threshold parameter $\mathcal{R}_{0}$. Additionally, the importance of the vector vertical transmission to the dynamics of the infection is studied through numerical simulations. It is important to remark that some prevention and control strategies against the Toxoplasmosis can be modeled using numerical simulations. In [4] a first approach to model the evolution of Toxoplasmosis disease in human population has been proposed, but considering that cat population remains constant and has an uniform behaviour as for the disease. However, in this chapter, we propose a model to study the evolution of Toxoplasmosis in a human population taking cats as vector of transmission. This model 
is more complex because two populations with interactions are included. The organization of this chapter is as follows. In the next section we formulate the mathematical model. Section 3.3 is devoted to analyse the steady states and find the threshold value $\mathcal{R}_{0}$ which determines the global dynamics and the outcome of the disease. Section 3.4 contains numerical results and finally, in Section 3.5, we present the conclusions.

\subsection{Mathematical model}

In this section, we present a continuous mathematical model for the transmission and evolution of Toxoplasmosis disease in human and cat populations. Following the basic ideas and structure of mathematical modeling in epidemiology, the Toxoplasmosis disease model will be developed under the next basic hypotheses [14, 46].

1. The total population $N_{h}(t)$ is divided into three subpopulations:

- Susceptible $S_{h}(t)$ : members of the human population who may become infected.

- Infected $I_{h}(t)$ : members of human population infected by the Toxoplasma Gondii parasite.

- Controlled $C_{h}(t)$ : members of the population who have been treated for the Toxoplasmosis.

2. The total population of cats $N_{c}(t)$ is divided into two subpopulations:

- Susceptible $S_{c}(t)$ : members of cats population who may become infected.

- Infected $I_{c}(t)$ : members of cats population infected by the Toxoplasma Gondii parasite.

3. A susceptible human can be infected through an effective direct or indirect contact with an infected cat and transit to the infected subpopulation $I_{c}(t)$. An infected human transits to the controlled subpopulation $C_{c}(t)$ at a rate $\gamma$.

4. A susceptible cat can be infected through an effective contact with an infected cat and transit to the infected subpopulation $I_{c}(t)$. A cat never recover from infection.

5. Both human and cat birth rate are assumed equal to their natural death rates, therefore constant population sizes are assumed.

6. All members of the susceptible subpopulations $S_{h}(t)$ and $S_{c}(t)$ have the same probability to be infected. 
7. Vertical transmission is assumed in human population, but in cat population it is assumed that occurs with probability $1-p_{c}$ where $p_{c}$ is the probability that a susceptible cat can be born from an infected one.

The total population of humans is denoted by

$N_{h}(t)=S_{h}(t)+I_{h}(t)+C_{h}(t)$,

and the total population of cats is denoted by

$N_{c}(t)=S_{c}(t)+I_{c}(t)$.

Under the above assumptions, the dynamic Toxoplasmosis disease model for human and cat population is depicted graphically in Fig. 3.1 and it is given analytically by the following first order nonlinear system of ordinary differential equations,

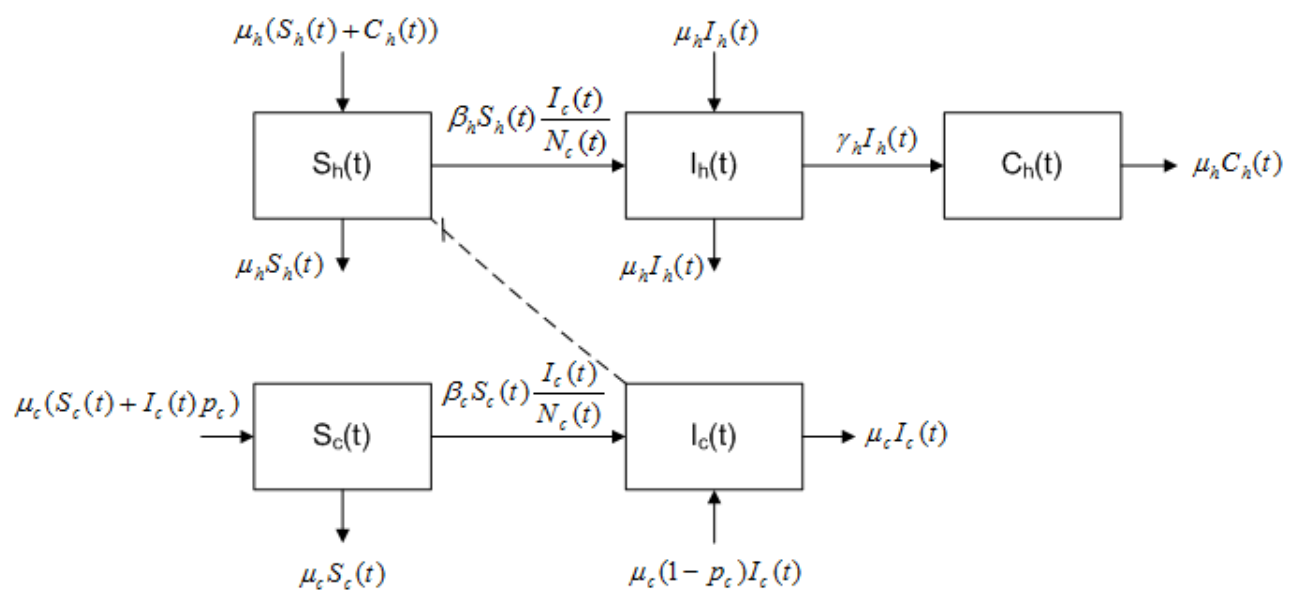

FiguRE 3.1: Flow diagram of the Toxoplasmosis disease model for human and cat populations as defined in system (3.1).

$$
\begin{aligned}
\dot{S}_{h}(t) & =\mu_{h} C_{h}(t)-\beta_{h} S_{h}(t) \frac{I_{c}(t)}{N_{c}(t)}, \\
\dot{I}_{h}(t) & =\beta_{h} S_{h}(t) \frac{I_{c}(t)}{N_{c}(t)}-\gamma I_{h}(t), \\
\dot{C}_{h}(t) & =\gamma I_{h}(t)-\mu_{h} C_{h}(t), \\
\dot{S}_{c}(t) & =\mu_{c} I_{c}(t) p_{c}-\beta_{c} S_{c}(t) \frac{I_{c}(t)}{N_{c}(t)}, \\
\dot{I}_{c}(t) & =\beta_{c} S_{c}(t) \frac{I_{c}(t)}{N_{c}(t)}-\mu_{c} I_{c}(t) p_{c} .
\end{aligned}
$$




\subsection{Stability analysis of the model}

In this section, the model (3.1) will be dynamically analysed to investigate the existence and stability of its associated equilibrium. This analysis allows us to study different scenarios about spread of the Toxoplasmosis disease in the human population caused by direct or indirect contact with infected cats.

\subsection{1. $\quad$ Scaling model}

Following the ideas developed in $[15,44]$ with regard to scaling population models, the next ratios (depend on time) are defined,

$$
X(t)=\frac{S_{h}(t)}{N_{h}(t)}, \quad Y(t)=\frac{I_{h}(t)}{N_{h}(t)}, Z(t)=\frac{C_{h}(t)}{N_{h}(t)}, \quad A(t)=\frac{S_{c}(t)}{N_{c}(t)}, \quad B(t)=\frac{I_{c}(t)}{N_{c}(t)} .
$$

Thus, using the system (3.1) and the equations (3.2) one gets,

$$
\begin{aligned}
\dot{X}(t) & =\mu_{h} Z(t)-\beta_{h} X(t) B(t), \\
\dot{Y}(t) & =\beta_{h} X(t) B(t)-\gamma Y(t), \\
\dot{Z}(t) & =\gamma Y(t)-\mu_{h} Z(t), \\
\dot{A}(t) & =\mu_{c} p_{c} B(t)-\beta_{c} A(t) B(t), \\
\dot{B}(t) & =\beta_{c} A(t) B(t)-\mu_{c} p_{c} B(t) .
\end{aligned}
$$

Since human and cat total populations have been normalised to unity, the following equations are obtained,

$$
Z(t)=1-X(t)-Y(t)
$$

and

$$
B(t)=1-A(t) .
$$

Thus, from (3.3), and using (3.4) and (3.5) we obtain the following simplified equivalent system 


$$
\begin{aligned}
\dot{X}(t) & =\mu_{h}(1-X(t)-Y(t))-\beta_{h} X(t)(1-A(t)), \\
\dot{Y}(t) & =\beta_{h} X(t)(1-A(t))-\gamma Y(t) \\
\dot{A}(t) & =\mu_{c} p_{c}(1-A(t))-\beta_{c} A(t)(1-A(t)) .
\end{aligned}
$$

For the sake of clarity and without loss of generality, analysis of equilibrium points are performed using the reduced system (3.6). Also, the dynamics of the system (3.6) are restricted in the positive invariant subset $\Omega \subset \mathbb{R}_{+}^{3}$ defined by

$$
\Omega=\left\{(X, Y, A)^{T} \in \mathbb{R}_{+}^{3} \mid \quad 0 \leq X \leq 1, \quad 0 \leq Y \leq 1, \quad 0 \leq A \leq 1\right\}
$$

\subsubsection{Equilibrium points of the model}

We denote by $\left(X^{*}, Y^{*}, A^{*}\right)$ the equilibrium points of system (3.6), i.e., the steady state where $\dot{X}^{*}=0, \dot{Y}^{*}=0, \dot{A}^{*}=0$ for all $t>t_{0}$. Therefore, from the last equation of system (3.6) one gets that

$$
B(t)=\left(1-A^{*}\right)\left[\mu_{c} p_{c}-\beta_{c} A^{*}\right]
$$

Therefore,

$$
A_{1}^{*}=1
$$

or

$$
A_{2}^{*}=\frac{\mu_{c} p_{c}}{\beta_{c}}
$$

Now, if (3.8) holds, then from second equation of system (3.6) we can obtain that $Y_{1}^{*}=0$, and from first equation of system (3.6) one gets that $X_{1}^{*}=1$. Hence, the disease free point is obtained as $\left(X_{1}^{*}, Y_{1}^{*}, A_{1}^{*}\right)=(1,0,1)$.

Also, if (3.9) holds, then from second equation of system (3.6) it follows that

$$
Y_{2}^{*}=\frac{\beta_{h} X^{*}\left(1-A_{2}^{*}\right)}{\gamma}
$$

and replacing in the first equation of system (3.6) it follows that 


$$
X_{2}^{*}=\frac{\mu_{h} \gamma}{\mu_{h} \gamma+\beta_{h}\left(1-A_{2}^{*}\right)\left(\mu_{h}+\gamma\right)}
$$

and that

$$
Y_{2}^{*}=\frac{\mu_{h} \beta_{h}\left(1-A_{2}^{*}\right)}{\mu_{h} \gamma+\beta_{h} \mu_{h}\left(1-A_{2}^{*}\right)+\beta_{h} \gamma\left(1-A_{2}^{*}\right)}
$$

Indeed, the model has the endemic point of coordinates $\left(X_{2}^{*}, Y_{2}^{*}, A_{2}^{*}\right)$

\subsubsection{Stability analysis}

Computing the Jacobian of system (3.6) evaluated at $\left(X^{*}, Y^{*}, A^{*}\right)$, one gets the following matrix

$$
J\left(X^{*}, Y^{*}, A^{*}\right)=\left(\begin{array}{ccc}
-\mu_{h}-\beta_{h}\left(1-A^{*}\right) & -\mu_{h} & \beta_{h} X^{*} \\
\beta_{h}\left(1-A^{*}\right) & -\gamma & -\beta_{h} X^{*} \\
0 & 0 & -\mu_{c} p_{c}-\beta_{c}+2 \beta_{c} A^{*}
\end{array}\right)
$$

\section{Disease free point}

In the absence of infection $\left(I_{h}=0\right)$ the model (3.6) has a disease free point $F_{1}^{*}=$ $\left(X^{*}, Y^{*}, A^{*}\right)=(1,0,1)$, and evaluating the Jacobian $J\left(F_{1}^{*}\right)$ it follows that

$$
J\left(X^{*}, Y^{*}, A^{*}\right)=\left(\begin{array}{rcc}
-\mu_{h} & -\mu_{h} & \beta_{h} \\
0 & -\gamma & -\beta_{h} \\
0 & 0 & \beta_{c}-\mu_{c} p_{c}
\end{array}\right)
$$

The stability of the equilibrium point $F_{1}^{*}$ is determined using the eigenvalues of $J\left(F_{1}^{*}\right)$. The disease free equilibrium point $F_{1}^{*}$ is locally asymptotically stable provided that the real part of eigenvalues are all negative. Thus, computing the eigenvalues of $J\left(F_{1}^{*}\right)$ we obtain that all are negative if

$$
\beta_{c}<\mu_{c} p_{c}
$$

Therefore, if we define 


$$
\mathcal{R}_{0}=\frac{\beta_{c}}{\mu_{c} p_{c}}<1
$$

the disease free point $F_{1}^{*}$ is locally asymptotically stable for $\mathcal{R}_{0}<1$. Thus, we have established the following Lemma:

Lemma 1. The disease free point $F_{1}^{*}$ is locally asymptotically stable if $\mathcal{R}_{0}<1$ and unstable if $\mathcal{R}_{0}>1$.

In addition, it can be shown that the disease free point $F_{1}^{*}$ is globally asymptotically stable for $\mathcal{R}_{0} \leq 1$. The following theorem can be established,

Theorem 1. If $\mathcal{R}_{0}<1$ then the disease free point $F_{1}^{*}$ is globally asymptotically stable.

Proof. In order to prove this, we consider the following Lyapunov function $V: \Omega \rightarrow \mathbb{R}_{+}$, defined by

$$
V(t)=V(X(t), Y(t), A(t))=\frac{1-A(t)}{\mu_{c} p_{c}}
$$

It is clear that $V \in C^{1}(\Omega)$ and $V(X(t), Y(t), A(t)) \geq 0$ for all $(X(t), Y(t), A(t))^{T} \in \Omega$. Next, taking the derivative of (3.15) with respect to time along of the solutions of system (3.6) and using the third equation of (3.6), we have

$$
\dot{V}(t)=-(1-A(t))-\mathcal{R}_{0} A(t)(1-A(t))=-\left(1-\mathcal{R}_{0} A(t)\right)(1-A(t)) .
$$

Since $1-A(t) \geq 0$ and $1-\mathcal{R}_{0} A(t)>0$ from (3.16) it follows that $\dot{V}(t) \leq 0$. Therefore, the Liapunov-Lasalle theorem guarantees the global stability of the disease free point $\left(X^{*}, Y^{*}, A^{*}\right)$, if $\mathcal{R}_{0}<1$.

\section{Endemic point}

Taking into account that, in this case, $I_{h} \neq 0$, from (3.9) (3.11) and (3.12) the model (3.6) has an endemic point $E_{2}^{*}=\left(X^{*}, Y^{*}, A^{*}\right)$. Evaluating the Jacobian $J\left(E_{2}^{*}\right)$ we obtain that

$$
J\left(E_{2}^{*}\right)=\left(\begin{array}{rcr}
L & -\mu_{h} & \frac{\beta_{h} \gamma}{H} \\
-\mu_{h}-L & -\gamma & -\frac{\beta_{h} \gamma}{H} \\
0 & 0 & M
\end{array}\right)
$$


where

$$
\begin{aligned}
H & =\gamma \mu_{h}+\left(\mu_{h}+\gamma\right) \beta_{h}\left(1-\frac{1}{\mathcal{R}_{0}}\right) \\
K & =\mu_{h} \beta_{h}\left(1-\frac{1}{\mathcal{R}_{0}}\right) \\
L & =-\mu_{h}-\beta_{h}\left(1-\frac{1}{\mathcal{R}_{0}}\right) \\
M & =-\mu_{c} p_{c}-\beta_{c}+\frac{2 \beta_{c}}{\mathcal{R}_{0}}
\end{aligned}
$$

The eigenvalues of $J\left(E_{2}^{*}\right)$ are calculated using $\operatorname{Det}\left(J\left(E_{2}^{*}\right)-\lambda I_{3}\right)=0$, i.e.,

$$
\operatorname{Det}\left(\begin{array}{rcr}
L-\lambda & -\mu_{h} & \frac{\beta_{h} \gamma}{H} \\
-\mu_{h}-L & -\gamma-\lambda & -\frac{\beta_{h} \gamma}{H} \\
0 & 0 & M-\lambda
\end{array}\right)=0
$$

Then, it follows that an eigenvalue is $\lambda_{1}=M$ and the other two eigenvalues are, $\lambda_{2}, \lambda_{3}$, the roots of the polynomial

$$
\lambda^{2}-\lambda(L-\gamma)+\mu_{h}\left(\mu_{h}-L\right)-L \gamma=0
$$

Now, the Eq. (3.18) has negative solutions if $L-\gamma<0$ and $\mu_{h}\left(\mu_{h}-L\right)-L \gamma>0$. On one hand

$$
-\gamma+L=-\gamma-\mu_{h}-\beta_{h}\left(1-\frac{1}{\mathcal{R}_{0}}\right)<0
$$

since $\mathcal{R}_{0}>1$, and

$$
\mu_{h}\left[\mu_{h}+\mu_{h}+\beta_{h}\left(1-\frac{1}{\mathcal{R}_{0}}\right)\right]+\left[\mu_{h}+\beta_{h}\left(1-\frac{1}{\mathcal{R}_{0}}\right)\right] \gamma>0
$$

Therefore, if $\mathcal{R}_{0}=\frac{\beta_{c}}{\mu_{c} p_{c}}>1$ the endemic point will be locally asymptotically stable. Then, the following Lemma has been established.

Lemma 2. The endemic point $E_{2}^{*}$ is locally asymptotically stable if $\mathcal{R}_{0}>1$ and unstable if $\mathcal{R}_{0}<1$. 
Based on the previous analysis we can summarize and state that there are two realistic equilibrium points: One is the disease free point and the other is the unique endemic equilibrium. $\mathcal{R}_{0}$ is the unique threshold parameter which determines the behaviour of the Toxoplasmosis spread. Assuming that the stability result for the endemic equilibrium is also global and assuming that initially there is, at least, one infectious cat, if $\mathcal{R}_{0}<1$, we expect the disease dies out, whereas if $\mathcal{R}_{0}>1$, then we expect the Toxoplasmosis disease tends to the unique endemic equilibrium, thereby establishing itself in the region.

\subsection{Numerical simulations}

In this section, we simulate different possible scenarios in order to observe the effect that some relevant parameters have on the dynamics of the Toxoplasmosis disease in human and cat populations. This is important from an epidemiological point of view, since it is possible to obtain the best strategy to tackle the disease. The first two scenarios are computed to check dynamic consistency between the theoretical results obtained in the previous section and the numerical simulations of the model. One scenario is the disease free with $\mathcal{R}_{0}<1$ and the other is the endemic with $\mathcal{R}_{0}>1$.

Another scenario is simulated varying the cats vertical transmission parameter $p_{c}$. This numerical simulation allows us to observe the effect of this parameter on the transmission dynamics of the Toxoplasmosis disease in human and cat populations.

In order to perform the numerical simulations, we take into account that in Chile approximately $55 \%$ of the cat population have antibodies against the Toxoplasma Gondii and that in Colombia approximately $47.74 \%$ of the population have antibodies against the Toxoplasma and only $1 \%$ is controlled $[4,28]$. Parameter values of human birth rate $\mu_{h}, \beta_{h}$ and transition to controlled population rate $\gamma$ were taken from [4]. The cats birth rate $\mu_{c}$ was obtained from zootechnic sources [16]. Thus, for numerical simulations, it is assumed as initial condition in the simulated scenarios the following values,

$$
X(0)=0.5253, \quad Y(0)=0.47 \quad \text { and } \quad A(0)=0.45
$$

The parameters of the model (3.6) are shown in Table 3.1.

Disease free point

Here, it is assumed a value for the parameter $\beta_{c}$ such that $\mathcal{R}_{0}<1$. As it can be observed in Fig. 3.2 and as expected from the theoretical results of previous section, the system tends to the disease free equilibrium point $\left(X_{1}^{*}, Y_{1}^{*}, A_{1}^{*}\right)=(1,0,1)$. 


\begin{tabular}{lr}
\hline Parameter & Values \\
\hline$\mu_{h}$ & 0.233 \\
$\beta_{h}$ & 0.0206 \\
$\mu_{c}$ & 0.066 \\
$p_{c}$ & 0.01 \\
$\gamma$ & Transmission rate \\
\hline
\end{tabular}

TABLE 3.1: Parameters of the model

\section{Endemic point}

Here, it is assumed a value of the parameter $\beta_{c}$ such that $\mathcal{R}_{0}>1$. As it can be observed in Fig. 3.3, and as expected from the theoretical results of previous section, the system tends to the endemic equilibrium point $\left(X^{*}=0.0603, Y^{*}=0.9386\right.$ and $\left.A^{*}=0.825\right)$.

High vertical transmission in cat population

Here, it is assumed a value of the parameter $\beta_{c}=0.0008$ and $P_{c}=0.0001$. As it can be observed in Fig. 3.4, the system tends to the endemic equilibrium point $X^{*}=$ $0.0112, Y^{*}=0.9878$ and $A^{*}=0.00825$. Notice that this equilibrium point has more proportion of infected cats and infected humans at the steady state than the previous case. This fact is expected because high vertical transmission leads to an increase in the infected cats from one generation to the next. Consequently, since there are more infected cats, transmission to humans increases.

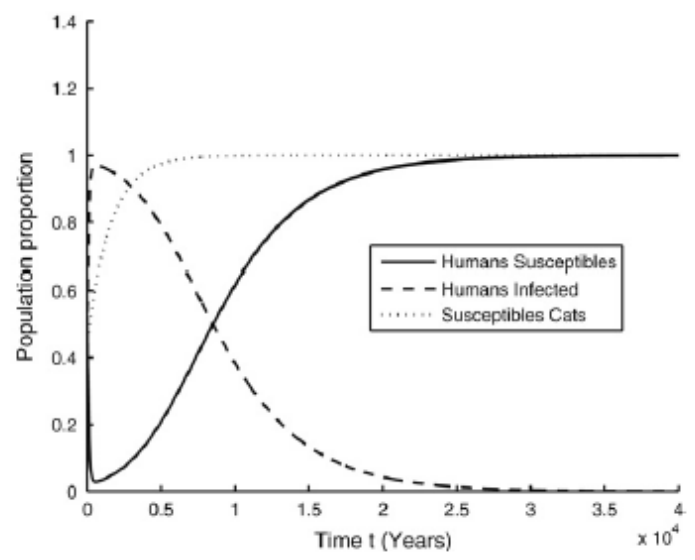

FIGURE 3.2: Dynamics of the different subpopulations when $\beta_{c}=0.00066, \gamma=0.000232$ and $\mathcal{R}_{0}=0.909 .\left(X_{1}^{*}=1, Y_{1}^{*}=0\right.$ and $\left.A_{1}^{*}=1\right)$ 


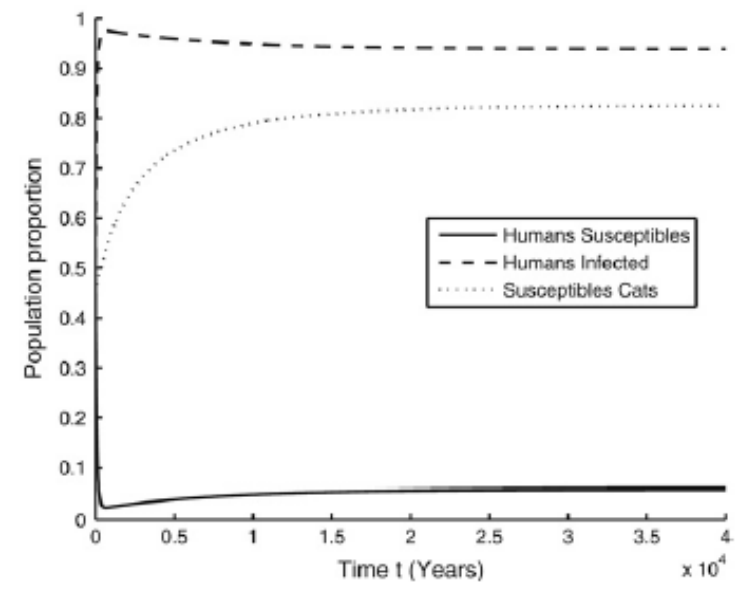

Figure 3.3: Dynamics of the different subpopulations when $\beta_{c}=0.0008, \gamma=0.000232$ and $\mathcal{R}_{0}=1.2121 .\left(X^{*}=0.0603, Y^{*}=0,9386\right.$ and $\left.A^{*}=0.825\right)$

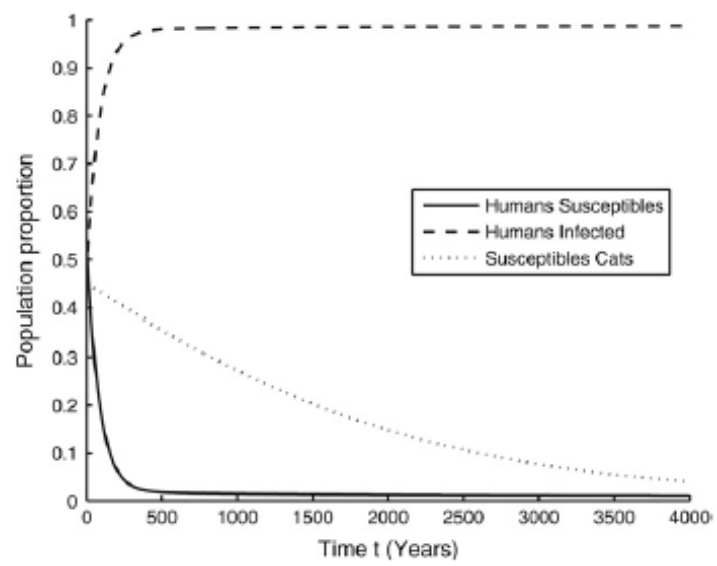

Figure 3.4: Dynamics of the different subpopulations when $\beta_{c}=0.0008, \gamma=0.000232$, $p_{c}=0.0001$ and $\mathcal{R}_{0}=121.21 .\left(X^{*}=0.0112, Y^{*}=0.9878\right.$ and $\left.A^{*}=0.00825\right)$

\subsection{Discussion and conclusions}

In this chapter a mathematical model was proposed to study the dynamics of Toxoplasmosis disease in human and cat populations. The model consists of modeling the interactions among susceptible and infective individuals of the two species assuming that the horizontal transmission of the disease to humans happens only through the contact with infected cats. Human population is divided into three classes or subpopulations, susceptibles $S_{h}(t)$, infectious $I_{h}(t)$ and controlled $C_{h}(t)$ and the cat population into two subpopulations, susceptibles $S_{c}(t)$ and infectious $I_{c}(t)$. We assume that both populations of cats and human are constant. Vertical and horizontal transmission in the cat 
population are considered. Transmission is assumed in the human population through an effective direct or indirect contact with an infected cat and vertical transmission is assumed with probability 1 . However, vertical transmission in cat population is assumed that occurs with probability $1-p_{c}$.

We show that the basic reproduction number $\mathcal{R}_{0}$ is a threshold value that completely determines the global dynamics and the outcome of the disease. If the threshold parameter $\mathcal{R}_{0}<1$, then the solution converges, in long term, to the disease free equilibrium point. Furthermore, if $\mathcal{R}_{0}>1$ the solution tends to the endemic equilibrium point. Additionally, the importance of cats vertical transmission to the dynamics of the infection is studied through numerical simulations. When a high vertical transmission is assumed in cat population, the endemic equilibrium point has a higher proportion of infected cats and infected humans at the steady state. This fact is expected from an intuitive point of view, since high vertical transmission implies easier transmission from one generation of cats to the next. Furthermore, since there are more infected cats, transmission to humans is also higher. Therefore, the dynamics of Toxoplasmosis disease is strongly influenced by vertical transmission in cat population. The numerical simulations show that this transmission favors the establishment of a constant endemic level in both populations. They also show an important increase in the endemic level of the cat and human population. This last result reinforces the idea that vertical transmission can be an important mechanism that favors the maintenance of the virus in areas with low human densities.

It is important to remark that the threshold number $\mathcal{R}_{0}$ is directly proportional to the probability of effective infectious contact among cats and does not depend on direct or indirect effective infectious contacts between humans and cats. Therefore, a control strategy to reduce Toxoplasmosis prevalence should focus on reducing this probability. One way of control is a vaccine program for cats. This also means that prevalence in human population may be reduced, but not eradicated, with hygienic actions and educations programs. In addition, probability of vertical transmission in cat population is an intrinsic value that seems invariable to control strategies. Therefore, this mechanism of transmission may be responsible for the permanence of the Toxoplasmosis infection as has been suggested in [24] for dengue virus.

Finally, it is important to mention that our mathematical model considers the evolution of Toxoplasmosis in human and cat populations with interaction among them, but it is necessary to have further knowledge of the parameter values involved in order to have a more accurate estimations of future health scenarios in the human and cat populations. Moreover, the parameter values of the model vary depending on the environment because these parameters should be adjusted for different cities or regions in different real world applications. Future work should include a model with vaccination and variable 
population size. More variables such as seasonal birth rate or oocyst survival time could be considered.

These result have been published in Computers and Mathematics with Applications 57(2009)1692 - 1700. 


\section{Chapter 4}

\section{Modeling dynamics of Babesiosis disease in bovines and ticks populations}

In this chapter we analyse the Babesiosis transmission dynamics on bovine and tick populations. Ticks play the role of infectious agent and vector of the protozoan Babesia hemo-parasite. Then, we set out a mathematical model with constant size population for the evolution of the infected bovines with Babesiosis and analyse its qualitative dynamics. Statistical data are used to estimate some of the model parameters. Numerical simulations of the model varying the parameters show different scenarios about the spread of the disease.

\subsection{Introduction}

Bovine babesiosis, caused by Babesia bovis and Babesia bigemina is one of the most important vector-transmitted diseases. Babesia is transmitted by the sting of ticks [62]. At least 1.3 billion of bovines all over the world are at risk of being infected because of their frequent exposure to Babesia bigemina [62].

Babesiosis has an important economic impact on the livestock sector of tropical regions. In warm and hot regions there is economic loss due to high bovine death, limiting the productivity increase of bovine derivatives [9]. Moreover, the climate conditions in these kind of regions favour the survival and reproduction of ticks and, consequently, bovines have a permanent contact with these vectors [9]. Furthermore, the vertical transmission 
in bovines and ticks is possible provided that the ovaries of the females are infected by parasites [51].

The parasite in bovines is detected by microscopical examination of blood [20]. A group of 2909 blood samples of bovine from 104 farms were analysed and the results showed a prevalence of $4.1 \%$ and $1.65 \%$ with presence of the parasitic forms in milk. Further analysis are required to generate new programs, prevention polices and control against the disease.

In this chapter, we propose and analyse a mathematical model of the babesiosis disease given by a system of nonlinear differential equations, in which the populations of bovines and ticks are considered to study their transmission dynamics. This model allow us to study the important role of ticks in the diseases dynamics. This modeling approach is the standard way to study the dynamic behaviour of diseases in populations from an epidemiological point of view (see [14, 29, 46]).

At the initial stages, the system is formed by five ordinary differential equations, which allow us to explain the influence of the epidemiological parameters considered in the evolution of the disease. Once the model is stated, steady states of the system and the basic reproduction number $\mathcal{R}_{0}$ are calculated. Then, we prove that the existence of the endemic equilibrium point depends on the value of threshold parameter $\mathcal{R}_{0}$ and demonstrate that it determines the local and the global stability of the disease free equilibrium point, as well as the endemic equilibrium point. This number should be regarded as a measure of the capacity of the ticks to transmit babesia. The basic reproduction number is a key concept in epidemiology and abundant literature has been devoted to $\mathcal{R}_{0}$ (see $[19,60,67])$.

The chapter is organized as follows. In Section 4.2 the mathematical model is set out. Section 4.3 is devoted to analyse the steady states and find out the threshold value $\mathcal{R}_{0}$. Moreover, conditions for local and global stability of the equilibrium points which determine the dynamics of the disease are also proven. Some numerical simulations are shown in Section 4.4. Finally, in Section 4.5, conclusions are presented.

\subsection{Mathematical model}

In this section, we introduce a continuous mathematical model for the transmission and evolution of the Babesiosis disease in bovine and tick populations. Following the basic ideas and structure of mathematical modeling in epidemiology, the Babesiosis disease model will be developed under the next hypotheses [14, 46]: 
- The total bovine population $N_{B}(t)$ is divided into three subpopulations: Cattle who may become infected (Susceptible $\bar{S}_{B}(t)$ ), bovine infected by the Babesia parasite (Infected $\bar{I}_{B}(t)$ ) and bovine who have been treated for the Babesiosis (Controlled $\left.\bar{C}_{B}(t)\right)$.

- The parameter $\mu_{B}$ is the birth rate of the cattle. The birth rate $\mu_{B}$ is assumed equal to the natural death.

- The total tick population $N_{T}(t)$ is divided into two subpopulations: Ticks who may become infected $\bar{S}_{T}(t)$ and ticks infected by the Babesia parasite $\bar{I}_{T}(t)$.

- The parameter $\mu_{T}$ is the birth rate of the ticks and it is assumed that it is equal to the death rate.

- A susceptible bovine can transit to the infected subpopulation $\bar{I}_{B}(t)$ because of an effective transmission due to a sting of an infected tick at rate $\beta_{B}[52]$.

- A susceptible tick can be infected if there is an effective transmission when it stings an infected bovine, at rate $\beta_{T}$ [52].

- We assume hundred percent vertical transmission in the bovine population $\mu_{B}$ [63]. In the tick population it occurs with probability $1-p$ where $p$ is the probability that a susceptible tick is born from an infected one [5].

- A fraction $\lambda_{B}$ of the infected cattle is controlled, i.e., they are treated against Babesia parasite.

- A fraction $\alpha_{B}$ of the controlled bovine may return to susceptible state [51].

- Homogeneous mixing is assumed, i.e., all susceptible cattle have the same probability to be infected and all susceptible ticks have the same probability to be infected.

Under the above hypotheses, the dynamic transmission of Babesiosis disease for bovine and tick population can be modeled by the following system of nonlinear first order differential equations:

$$
\begin{aligned}
\bar{S}_{B}^{\prime}(t) & =\mu_{B}\left(\bar{S}_{B}(t)+\bar{C}_{B}\right)+\alpha_{B} \bar{C}_{B}(t)-\mu_{B} \bar{S}_{B}(t)-\beta_{B} \bar{S}_{B}(t) \frac{\bar{I}_{T}(t)}{N_{T}(t)} \\
\bar{I}^{\prime}{ }_{B}(t) & =\mu_{B} \bar{I}_{B}+\beta_{B} \bar{S}_{B}(t) \frac{\bar{I}_{T}(t)}{N_{T}(t)}-\mu_{B} \bar{I}_{B}-\lambda_{B} \bar{I}_{B}(t) \\
\bar{C}^{\prime}{ }_{B}(t) & =\lambda_{B} \bar{I}_{B}(t)-\left(\mu_{B}+\alpha_{B}\right) \bar{C}_{B}(t) \\
\bar{S}^{\prime}{ }_{T}(t) & =\mu_{T}\left(\bar{S}_{T}+p \bar{I}_{T}\right)-\beta_{T} \bar{S}_{T}(t) \frac{\bar{I}_{B}(t)}{N_{B}(t)}-\mu_{T} \bar{S}_{T}(t) \\
\bar{I}^{\prime}{ }_{T}(t) & =\beta_{T} \bar{S}_{T}(t) \frac{\bar{I}_{B}(t)}{N_{B}(t)}+(1-p) \mu_{T} \bar{I}_{T}(t)-\mu_{T} \bar{I}_{T}(t) .
\end{aligned}
$$


The diagram is depicted in Fig. 4.1

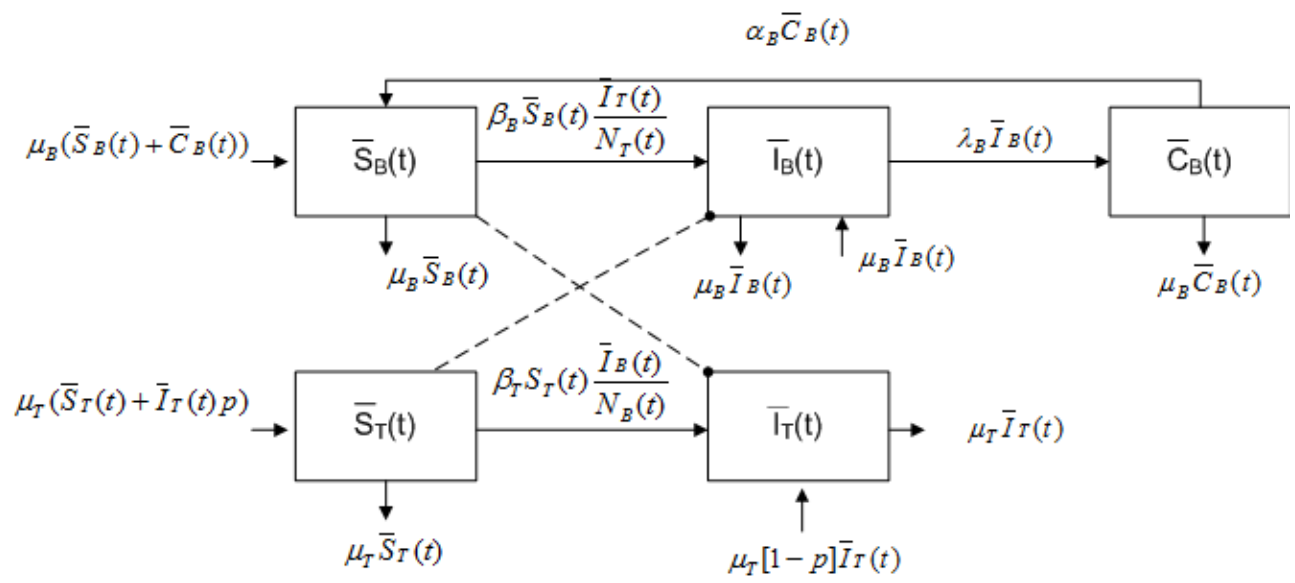

Figure 4.1: Dynamics of the Babesiosis disease in bovine and tick populations

Simplifying the system (4.1), we have

$$
\begin{aligned}
{\overline{S^{\prime}}}_{B}(t) & =\left(\mu_{B}+\alpha_{B}\right) \bar{C}_{B}(t)-\beta_{B} \bar{S}_{B}(t) \frac{\bar{I}_{T}(t)}{N_{T}(t)}, \\
\bar{I}^{\prime}{ }_{B}(t) & =\beta_{B} \bar{S}_{B}(t) \frac{\bar{I}_{T}(t)}{N_{T}(t)}-\lambda_{B} \bar{I}_{B}(t), \\
\bar{C}^{\prime}{ }_{B}(t) & =\lambda_{B} \bar{I}_{B}(t)-\left(\mu_{B}+\alpha_{B}\right) \bar{C}_{B}(t), \\
\bar{S}^{\prime} T(t) & =\mu_{T} p \bar{I}_{T}-\beta_{T} \bar{S}_{T}(t) \frac{\bar{I}_{B}(t)}{N_{B}(t)} \\
\bar{I}^{\prime} T & =\beta_{T} \bar{S}_{T}(t) \frac{\bar{I}_{B}(t)}{N_{B}(t)}-\mu_{T} p \bar{I}_{T}(t) .
\end{aligned}
$$

Adding, from the three first equations, we can obtain,

$$
N_{B}^{\prime}(t)=\bar{S}_{B}^{\prime}(t)+\bar{I}_{B}^{\prime}(t)+\bar{C}_{B}^{\prime}(t)=0,
$$

and therefore the bovine population is constant. Analogously, adding the two last equations we have that

$$
N_{T}^{\prime}(t)=\bar{S}_{T}^{\prime}(t)+\bar{I}_{T}^{\prime}=0
$$

and likewise the tick population is also constant.

All parameters in this model are non-negative. It is easy to prove that (4.2) is well-posed, i.e., if the initial data $\left(\bar{S}_{B}\left(t_{0}\right), \bar{I}_{B}\left(t_{0}\right), \bar{C}_{B}\left(t_{0}\right), \bar{S}_{T}\left(t_{0}\right), \bar{I}_{T}\left(t_{0}\right)\right)$ are in the region $\mathbb{R}_{+}^{5}$, then the solutions are defined for all time $t \geq 0$ and remain in this region. 
Introducing the following proportions in system (4.2),

$$
S_{B}=\frac{\bar{S}_{B}}{N_{B}}, I_{B}=\frac{\bar{I}_{B}}{N_{B}}, C_{B}=\frac{\bar{C}_{B}}{N_{B}}, S_{T}=\frac{\bar{S}_{T}}{N_{T}}, I_{T}=\frac{\bar{I}_{T}}{N_{T}}
$$

and using the relations $C_{B}(t)=1-S_{B}(t)-I_{B}(t)$ and $S_{T}(t)=1-I_{T}(t)$, we can obtain the following system that describes the dynamics of the proportion of cattle in each subpopulation,

$$
\left\{\begin{aligned}
S_{B}^{\prime}(t) & =\left(\mu_{B}+\alpha_{B}\right)\left(1-S_{B}(t)-I_{B}(t)\right)-\beta_{B} S_{B}(t) I_{T}(t) \\
I_{B}^{\prime}(t) & =\beta_{B} S_{B}(t) I_{T}(t)-\lambda_{B} I_{B}(t) \\
I_{T}^{\prime}(t) & =\beta_{T}\left(1-I_{T}(t)\right) I_{B}(t)-\mu_{T} p I_{T}(t) .
\end{aligned}\right.
$$

The region, $\Omega=\left\{\left(S_{B}, I_{B}, I_{t}\right) \mid 0 \leq S_{B}+I_{B} \leq 1,0 \leq I_{T} \leq 1\right\}$ is a positive invariant set for the system (4.3) and we consider it as the state space of this system.

\subsection{Analysis of the model}

In this section, we study the existence and stability of the equilibrium points of the system (4.3). This analysis allows us to study different scenarios concerning the spread of Babesiosis disease in the bovine population caused by direct contact with infected ticks. In order to do that, we shall use the following threshold parameter:

$$
\mathcal{R}_{0}=\frac{\beta_{B} \beta_{T}}{\lambda_{B} \mu_{T} p}
$$

\subsubsection{Model equilibrium points}

Proposition 1. The system (4.3) has a disease free equilibrium point and it is given by $\left(S_{B_{1}}^{*}, I_{B_{1}}^{*}, I_{T_{1}}^{*}\right)=(1,0,0)$ for all the values of the parameters in this system and only if $\mathcal{R}_{0}>1$, there is an endemic equilibrium point (unique) $\left(S_{B_{2}}^{*}, I_{B_{2}}^{*}, I_{T_{2}}^{*}\right)$ in the interior of $\Omega$.

Proof. We denote by $\left(S_{B_{i}}^{*}, I_{B_{i}}^{*}, I_{T_{i}}^{*}\right)$ the equilibrium points of system (4.3), i.e, the steady state where $S_{B}^{\prime}=0, I_{B}^{\prime}=0, I_{T}^{\prime}=0$ for all $t>t_{0}$. Then, the disease free point is $\left(S_{B_{1}}^{*}, I_{B_{1}}^{*}, I_{T_{1}}^{*}\right)=(1,0,0)$ and the endemic point is given by,

$$
S_{B_{2}}^{*}=\frac{\beta_{T} \lambda_{B}\left(\alpha_{B}+\mu_{B}\right)+p \lambda_{B}\left(\alpha_{B}+\lambda_{B}+\mu_{B}\right) \mu_{T}}{\beta_{T}\left(\alpha_{B}\left(\beta_{B}+\lambda_{B}\right)+\lambda_{B} \mu_{B}+\beta_{B}\left(\lambda_{B}+\mu_{B}\right)\right)}
$$




$$
\begin{aligned}
I_{B_{2}}^{*} & =\frac{\left(\alpha_{B}+\mu_{B}\right)\left(\beta_{B} \beta_{T}-p \lambda_{B} \mu_{T}\right)}{\beta_{T}\left(\alpha_{B}\left(\beta_{B}+\lambda_{B}\right)+\lambda_{B} \mu_{B}+\beta_{B}\left(\lambda_{B}+\mu_{B}\right)\right)} \\
I_{T_{2}}^{*} & =\frac{\left(\alpha_{B}+\mu_{B}\right)\left(\beta_{B} \beta_{T}-p \lambda_{B} \mu_{T}\right)}{\beta_{T} \beta_{B}\left(\alpha_{B}+\mu_{B}\right)+p \beta_{B}\left(\alpha_{B}+\lambda_{B}+\mu_{B}\right) \mu_{T}}
\end{aligned}
$$

Notice that if $\mathcal{R}_{0}>1$, then $\left(\beta_{B} \beta_{T}-p \lambda_{B} \mu_{T}\right)>0$. Then, taking into account that all model parameters are positive, we have

$$
S_{B_{2}}^{*}, I_{B_{2}}^{*}, I_{T_{2}}^{*}>0
$$

Thus, there is a (unique) endemic equilibrium point $\left(S_{B_{2}}^{*}, I_{B_{2}}^{*}, I_{T_{2}}^{*}\right)$ in the interior of $\Omega$. Now, we are going to demonstrate that if $\mathcal{R}_{0} \leq 1$ the unique equilibrium point in $\Omega$ is the disease free point $\left(S_{B_{1}}^{*}, I_{B_{1}}^{*}, I_{T_{1}}^{*}\right)=(1,0,0)$.

We distinguish two cases:

- $\mathcal{R}_{0}<1$ : In this situation, $\beta_{B} \beta_{T}-p \lambda_{B} \mu_{T}<0$. Thus, looking at the fractions that define the coordinates of the endemic point, it is easy to check that $I_{B_{2}}^{*}, I_{T_{2}}^{*}<0$, except when $\mu_{B}+\alpha_{B}=0$. However, this is not possible because the bovine birth rate $\mu_{B}>0$. Therefore, when $\mu_{B}+\alpha_{B} \neq 0$ this point remains in the outside of the region $\Omega$.

- $\underline{\mathcal{R}_{0}=1}$ : In this case, since $\beta_{B} \beta_{T}-p \lambda_{B} \mu_{T}=0$, we have that $I_{B_{2}}^{*}, I_{T_{2}}^{*}=0$ and $S_{B 2}^{*}=1$.

Observe that this last case has real sense because, when $\mathcal{R}_{0}=1$, we have $I_{B_{2}}^{*}, I_{T_{2}}^{*}=0$, i.e., the number of infected are 0 , and therefore, the endemic point cannot exist.

\subsubsection{Stability analysis}

Computing the Jacobian of system (4.3) evaluated at the disease free point, one gets the following matrix 


$$
J(1,0,0)=\left(\begin{array}{rcc}
-\left(\alpha_{B}+\mu_{B}\right) & -\left(\alpha_{B}+\mu_{B}\right) & -\beta_{B} \\
0 & -\lambda_{B} & \beta_{B} \\
0 & \beta_{T} & -\mu_{T} p
\end{array}\right)
$$

and, consequently, the eigenvalues of $J\left(F_{1}^{*}\right)$ are

$$
\begin{gathered}
\gamma_{1}=-\left(\alpha_{B}+\mu_{B}\right) \\
\gamma_{2,3}=\frac{-\left(\lambda_{B}+\mu_{T} p\right) \pm \sqrt{4 \beta_{B} \beta_{T}+\lambda_{B}^{2}-2 \lambda_{B} \mu_{T} p+\mu_{T}^{2} p^{2}}}{2} .
\end{gathered}
$$

The stability of the equilibrium point $F_{1}^{*}$ is determined using the eigenvalues of $J\left(F_{1}^{*}\right)$. The disease free equilibrium point $F_{1}^{*}$ is locally asymptotically stable if the real part of eigenvalues are all negative. In fact, the eigenvalues of $J\left(F_{1}^{*}\right)$ are negative, if

$$
\mathcal{R}_{0}=\frac{\beta_{B} \beta_{T}}{\lambda_{B} \mu_{T} p}<1
$$

Thus, we can state the next result.

Lemma 1. The disease free point $F_{1}^{*}$ is locally asymptotically stable if $\mathcal{R}_{0}<1$ and unstable if $\mathcal{R}_{0}>1$.

Moreover, we can prove the following Theorem.

Theorem 1. If $\mathcal{R}_{0}<1$, then the disease free point $F_{1}^{*}$ is globally asymptotically stable.

Proof. First of all, we are going to move the origin of the coordinate system to the position of our disease free point. To do that, we only have to make the change of variables

$$
X_{B}=1-S_{B}
$$

and the system (4.3) becomes

$$
\left\{\begin{aligned}
X_{B}^{\prime}(t) & =-\left(\mu_{B}+\alpha_{B}\right) X_{B}(t)+\left(\mu_{B}+\alpha_{B}\right) I_{B}(t)+\beta_{B} I_{T}(t)-\beta_{B} X_{B}(t) I_{T}(t) \\
I_{B}^{\prime}(t) & =-\lambda_{B} I_{B}(t)+\beta_{B} I_{T}(t)-\beta_{B} X_{B}(t) I_{T}(t) \\
I_{T}^{\prime}(t) & =\beta_{T} I_{B}(t)-\mu_{T} p I_{T}(t)-\beta_{T} I_{B}(t) I_{T}(t)
\end{aligned}\right.
$$


To abbreviate, we refer $F\left(X_{B}(t), I_{B}(t), I_{T}(t)\right)$ as the function defining this system of ordinary differential equations, that is, the system (4.11) can be expressed as

$$
\left(X_{B}^{\prime}(t), I_{B}^{\prime}(t), I_{T}^{\prime}(t)\right)=F\left(X_{B}(t), I_{B}(t), I_{T}(t)\right) .
$$

At this point, we consider the function $V: \Omega \rightarrow \mathbb{R}_{+}$defined by

$$
V(t)=V\left(X_{B}(t), I_{B}(t), I_{T}(t)\right)=\beta_{T} I_{B}(t)+\lambda_{B} I_{T}(t) .
$$

This function $V \in \mathcal{C}^{1}(\Omega)$ and the escalar product $\nabla V\left(X_{B}, I_{B}, I_{T}\right) \cdot F\left(X_{B}, I_{B}, I_{T}\right)$ is given by

$\beta_{T}\left(-\lambda_{B} I_{B}(t)+\beta_{B}(t) I_{T}(t)-\beta_{B} X_{B}(t) I_{T}(t)\right)+\lambda_{B}\left(\beta_{T} I_{B}(t)-\mu_{T} p I_{T}(t)-\beta_{T} I_{B}(t) I_{T}(t)\right)$.

Simplifying this last expression, we have,

$$
\left.\left(\beta_{T} \beta_{B}-\lambda_{B} \mu_{T} p\right) I_{T}(t)-\beta_{T} \beta_{B} X_{B}(t) I_{T}(t)-\lambda_{B} \beta_{T} I_{B}(t) I_{T}(t)\right)
$$

Under the hypothesis $\mathcal{R}_{0} \leqslant 1$, we have that $\beta_{T} \beta_{B}-\lambda_{B} \mu_{T} p \leqslant 0$. Taking into account that all the parameters and variables appearing are greater than 0 , we get

$$
\nabla V\left(X_{B}, I_{B}, I_{T}\right) \cdot F\left(X_{B}, I_{B}, I_{T}\right) \leqslant 0 .
$$

Consequently, the LaSalle-Lyapunov theorem guarantees the global stability of the disease free point $\left(S_{B_{1}}^{*}, I_{B_{1}}^{*}, S_{T_{1}}^{*}\right)$ if $\mathcal{R}_{0} \leqslant 1$.

\subsection{Numerical simulations}

In this section, we simulate different possible scenarios in order to observe the effect that some relevant parameters have on the dynamics of Babesia disease in bovine and tick populations. This is important from an epidemiological point of view, since it is possible to simulate strategies to tackle the disease. The first two scenarios are computed to illustrate the dynamic consistency between the theoretical results obtained in the previous section and the numerical simulations. One scenario is the disease free equilibrium with $\mathcal{R}_{0}<1$ and other is the endemic equilibrium with $\mathcal{R}_{0}>1$. 
Additionally, another scenario is simulated by varying the transmission parameters $\beta_{B}$ and $\beta_{T}$; if the value of the parameter $\beta_{B}$ is bigger than 0.005 , then there is a growth of the infected bovine subpopulation [18]. This numerical simulation allows us to observe the effect of these parameters on the transmission dynamics of Babesiosis disease in bovine and tick populations.

In order to perform the numerical simulations we take into account that $60 \%$ of ticks in North Colombia are infected by Babesia, approximately $51.84 \%$ of the bovines are infected by Babesia, only $10 \%$ are controlled [68] and the vertical transmission is $90 \%$ [63]. Thus, we assume these figures as initial condition for numerical simulation,

$$
S_{B}(0)=0.3816 \quad I_{B}(0)=0.5184 \quad I_{T}(0)=0.60
$$

The parameters of the model (4.3) are positive, and the following Table 4.1 shows its values for North Colombia.

\begin{tabular}{|r|l|l|l|l|l|l|l|}
\hline Parameter & $\mu_{B}$ & $\mu_{T}$ & $\lambda_{B}$ & $\alpha_{B}$ & $p$ & $\beta_{B}$ & $\beta_{T}$ \\
\hline \hline Values & 0.0002999 & 0.001609 & 0.000265 & 0.001 & 0.1 & 0.00061 & 0.00048 \\
\hline
\end{tabular}

TABLE 4.1: Parameters for simulation. The values $\beta_{B}, \beta_{T}$ and $\alpha_{B}$ have been calculated assuming an ecologic stability.

Parameter values of bovines birth rate $\mu_{B}$ and transition to controlled population rate $\lambda_{B}$ have been provided by Efrain Benavides Ortiz Ph.D, Group of research Animal Biotechnology GIBA, Faculty of Agrarian Sciences, Politécnico Colombiano Jaime Isaza Cadavid, October 2008, Medellín-Colombia (not published data). The tick birth rate $\mu_{T}$ has been obtained in [69].

\section{Ecologic stability}

For the first simulation we assume that the spread of Babesiosis in the populations of cattle and ticks in Colombia is in equilibrium (ecologic stability), i.e., proportions of the subpopulations (susceptible cattle, infected cattle and infected ticks) are positive and constant over time. This scenario is possible taking the parameter original values $\left(\mu_{B}\right.$, $\mu_{T}, \alpha_{B}$ and $\left.p\right)$ constants over time and estimate or fit the parameters $\left(\beta_{B}, \beta_{T}\right.$ and $\left.\alpha_{B}\right)$ to obtain the ecologic stability. See Fig. 4.2.

In this case, the initial condition is the same as the endemic equilibrium point $(0.3816$, $0.5184,0.60)$ and the eigenvalues of its Jacobian are $(-0.7489,-0.7480,-0.7058)$, all negative. Therefore, the equilibrium point is locally asymptotically stable. 


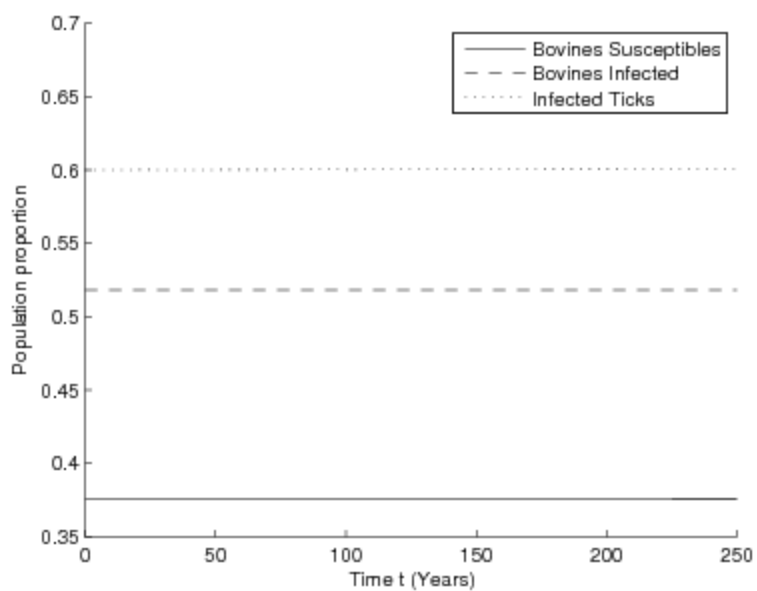

FIGURE 4.2: Ecologic stability, when $\beta_{B}=0.00061, \beta_{T}=0.00048, \alpha_{B}=0.001$ and $\mathcal{R}_{0}=6.8$.

Disease free point

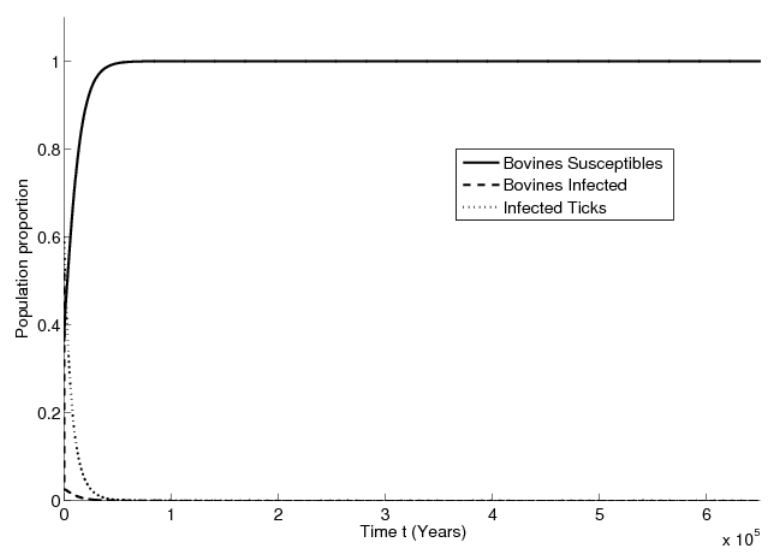

FiguRE 4.3: Dynamics of the different subpopulations when $\beta_{B}=0.0003, \lambda_{B}=0.0265$, $p=0.1$ and $\mathcal{R}_{0}=0.33$

Here, we assume a scenario where the transmission of Babesia is downturn $\beta_{B}=0.0003$ in the bovine subpopulation, a value for the parameter $\lambda_{B}=0.0265$ that shows appropriate control measures against the disease. The other parameters remain constant over time, and then $\mathcal{R}_{0}<1$. We can see in Fig. 4.3 that, as expected from the theoretical results of previous section, the model solution tends to the disease free equilibrium point.

\section{Endemic point stability}

In these two simulations, we take different values for initial conditions that simulate endemic situations of the disease and that show both tend to the same endemic equilibrium point. This exhibits the global asymptotic stability of the endemic point. We simulate a 


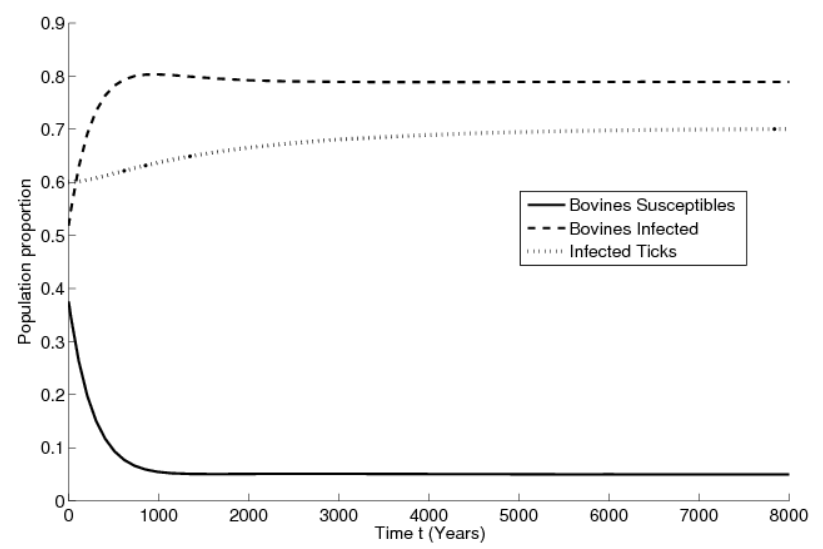

Figure 4.4: Dynamics of the different subpopulations when $\beta_{B}=0.006$ and $p=0.1$, with initial condition $S_{B}(0)=0.3816, \quad I_{B}(0)=0.5184, \quad S_{T}(0)=0.60$ and $\mathcal{R}_{0}=67.54$.

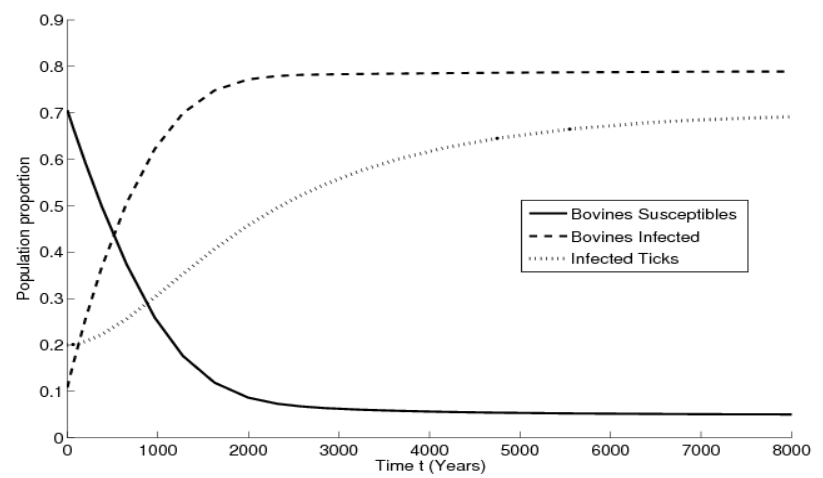

FiguRE 4.5: Dynamics of the different subpopulations when $\beta_{B}=0.006$ and $p=0.1$, with initial condition $S_{B}(0)=0.70, \quad I_{B}(0)=0.10, \quad S_{T}(0)=0.20$ and $\mathcal{R}_{0}=67.54$.

scenario of high rate of transmission of Babesia in bovine population with a $\beta_{B}$ greater than $0.005[18]$ and high rate of vertical transmission in the tick population with a value for the parameter $p=0.1$. The other parameters remain constant over time and $\mathcal{R}_{0}>1$ (see in Figs. 4.4, 4.5). In both cases, the endemic equilibrium point is $(0.0498,0.7893$, $0.70)$.

\section{The sensitivity of the transmission parameters}

In these numerical simulations, the variation of the transmission parameters $\beta_{B}$ and $\beta_{T}$ allows us to observe the effect of these parameters on the dynamics of transmission of the disease in the bovine and tick population. The results can be seen in Fig. 4.6 

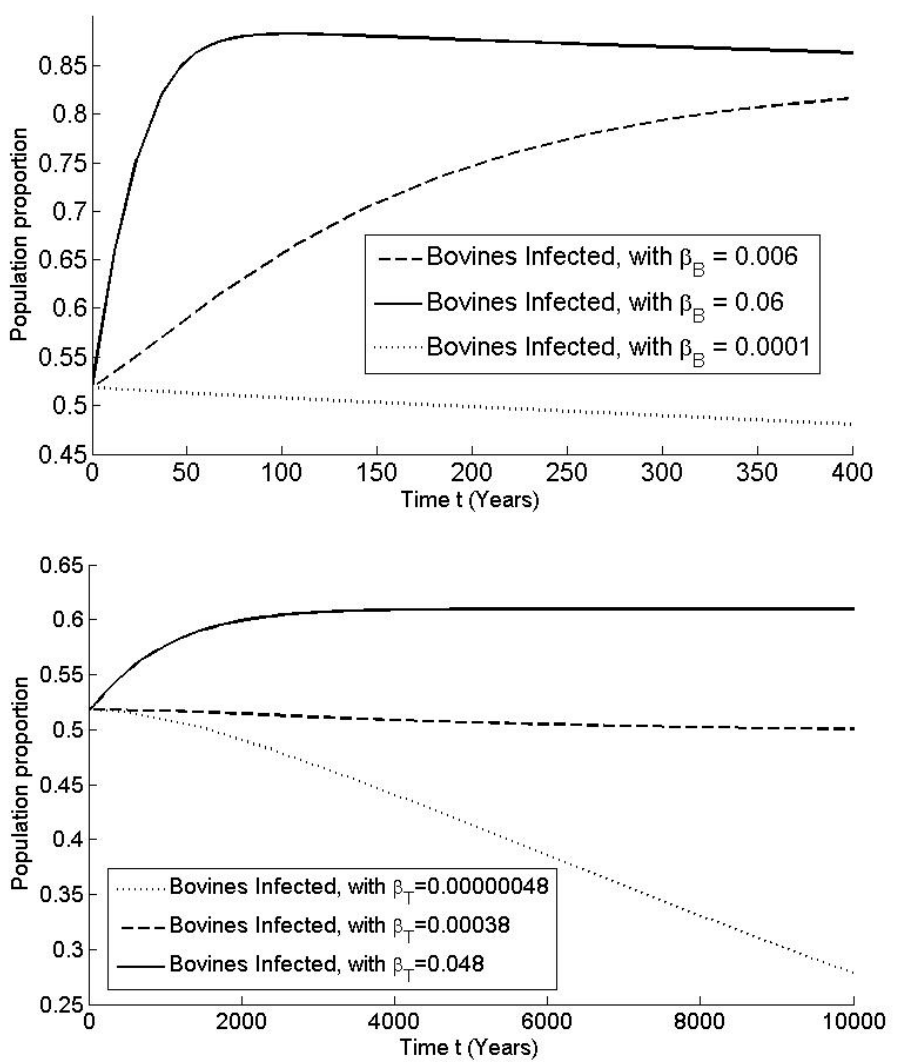

FiguRE 4.6: The dynamics of the subpopulations is sensitive to the parameters $\beta_{B}$ and $\beta_{T}$.

\subsection{Conclusions}

We proved that the basic reproduction number $\mathcal{R}_{0}$ is a threshold value that completely determines the global dynamics and the outcome of the disease. On one hand, if the threshold parameter $\mathcal{R}_{0}<1$, then the solution converges to the disease free equilibrium point. On the other hand, if $\mathcal{R}_{0}>1$ the solution converges to the endemic equilibrium point. When a high rate of vertical transmission in the tick population and a high rate of transmission of the parasite in the bovine population are assumed, the endemic equilibrium point has a higher proportion of infected ticks and infected bovines. These facts are expected from an intuitive point of view. Furthermore, if there are more infected ticks, transmission to bovines will be greater. Therefore, the dynamics of Babesiosis disease are influenced by the sensitivity of the parameters transmission $\beta_{B}$ and $\beta_{T}$. Because of this, it is possible to state that this transmission helps to establish a constant endemic level in both populations.

It is worthwhile to remark that the threshold number $\mathcal{R}_{0}$ is directly proportional to the probability of effective contacts among bovines infected and among ticks infected. Therefore, a control strategy to reduce Babesiosis prevalence should focus on reducing 
this probability. One way of control could be to fumigate with tick killer insecticides. In this form, prevalence in bovine population may be reduced. However, probability of vertical transmission in tick population is an intrinsic value that seems to be invariant to control strategies. Therefore, this mechanism of transmission may be responsible for the permanence of the Babesiosis infection as it has been suggested in [23] for dengue.

Finally, it is important to mention that our mathematical model considers the evolution of Babesiosis in the bovine and tick populations with interaction among them, but it is necessary to have further knowledge of the parameter values involved in order to have more accurate estimation of future scenarios in the bovine and tick populations. Moreover, the parameter values of the model may vary depending on the environment. Paper accepted in Mathematical Methods in Applied Sciences, March 2011, doi 10.1002/mma .1544. 


\section{Bibliography}

[1] Ahlbom, A., And Norell, S. Fundamentos de Epidemiología. Siglo XXI de Espaa Editores, 1995.

[2] Ambroise, P., And Eskild, T. Congenital Toxoplasmosis: Scientific Background, Clinical Management and Control. Springer, 2000.

[3] Anderson, M. Bulletin of mathematical Biology, vol. 53. Springer New York, 2009.

[4] Aranda, D. F., Arenas, A. J., González-Parra, G. C., and Villanueva, R. J. Mathematical model of toxoplasmosis disease in varying size population. $J$. Comp Math Appli 56 (2008), 690-696.

[5] Aranda, D. F., Arenas, A. J., González-Parra, G. C., Villanueva, R. J., AND JóDAR, L. A. Dynamics of a model of toxoplasmosis disease in human and cat population. J. Comp Math Appli 57(10) (2009), 1692-1700.

[6] Babes, V. National institutes of health. Am J Public Health (N Y) 17(6), 6 (1927), 615 .

[7] Bahía-Oliveira, M., Jones, J. L., Azevedo-Silva, J., And Alves, C. Highly endemic, waterborne toxoplasmosis in north rio de janeiro estate brazil. J. Emerg Infect Dis 9 (2003), 55-62.

[8] Beaver, P. C., Hung, R. C., And Cuup, E. C. Clinical Parasitology, 9th ed. Lea \& Febiger, 1984.

[9] Benavides, E. Considerations with respect to the epizootilogia of anaplasmosis and babesiosis in the bovines. ACOVEZ 9, 31 (1985), 4-11.

[10] Boothroyd, J. C., And Grigg, M. E. Population biology of toxoplasma gondii and its relevance to human infection: Do different strains cause different disease? J. Curr Opin Microbiol 5(4), 4 (2002), 438-442. 
[11] Bossi, P., Paris, L., Caumes, E., Katlama, C., Danis, M., and Bricaire, F. Severe acute disseminated toxoplasmosis acquired by an immunocompetent patient in french guiana. Scandinavian Journal of Infectious Diseases 34(4) (2004), $311-314$.

[12] Botero, D., And Restrepo, M. Parasitosis Humanas, fourth edition ed. Corporación para Investigaciones Biológicas, 2005.

[13] Bowman, D. Geogis' Parasitology for Veterinarians, ninth edition ed. Saunders, 2002.

[14] Brauer, F., And Castillo-Chavez, C. Mathematical Models in Population Biology and Epidemiology. Springer, 2001.

[15] Castillo-Chavez, C., And Martcheva, M. Diseases with chronic stage in population with varying size. J. Math. Biosci 182(1) (2003), 1-25.

[16] CiAam-Centro-Integral-Acogida-Animales. Control de natalidad en perros y gatos. http://www.centrodeacogida.org/control_de_natalidad.asp, April 2008.

[17] Cortazar, T., Hernández, J., Echeverry, M., and Camacho, M. Papel de la vacuola parasitófora de macrófagos de ratón infectados por leishmania amazonensis en la adquisición de moléculas. J. Biomédica 26, 1 (2006), 26-37.

[18] Cuéllar, H., Cuéllar, A., Chávez, G., Carrique-Mas, J., and Walker, A. Estudio sobre babesiosis y anaplasmosis en relación con la carga de garrapatas en terneros lecheros del oriente boliviano. Center for Tropical Veterinary Medicine 31(001) (1999), 39-46.

[19] Dietz, K. The estimation of the basic reproduction number for infectious diseases. Stat Methods Med Res 2(6) (1993), 2341.

[20] Domínguez-Alpizar, J. L., Rodríguez-Vivas, R. I., Oura, C., And CobGalera, L. A. Determinación de la especificidad y sensibilidad de las técnicas de ensayo inmunoenzimático indirecto y de inmunofluorescencia indirecta para el diagnóstico de babesia bovis. J. Biomed 6, 1 (1995), 17-23.

[21] Duh, D., Petrovec, M., And Avsic-Zupanc, T. Diversity of the babesia infecting european sheep ticks (ixodes ricinus). J. Clin Microbiol 39(9), 9 (2001), 3395-3397.

[22] Esteva, L., And Vargas, C. Analysis of a dengue disease transmission model. J. Mathematical Biosciences 150(2) (1998), 131-151. 
[23] Esteva, L., And Vargas, C. A model for dengue disease with variable human population. J. Math. Biol. 38 (1999), 220-240.

[24] Esteva, L., and Vargas, C. Influence of vertical and mechanical transmission on the dynamics of dengue disease. J. Mathematical Biosciences 167(1), 1 (2000), $51-64$.

[25] Frenkel, J. K., And Ruiz, A. Human toxoplasmosis and cat contact in costa rica. Amer J. Tropi Med Hyg 29(6), 6 (1980), 1167-1180.

[26] Gómez-Marín, J. Toxoplasmosis: Un problema de salud pública en colombia. Rev. Salud Pública 4 (2002), 7-10.

[27] Gómez-Marín, J., López-Castillo, C., and Díaz-Ramírez, J. Risk factors for toxoplasma gondii infection in pregnant women in armenia, colombia. Rev. Salud Pública 7(2) (2005), 180-190.

[28] Gómez-Marin, J., Montoya, M., and Castao-Osorio, J. A maternal screening program for congenital toxoplasmosis in quindio, colombia an application of mathematical models to estimate incidences using age-stratified data. Am J Trop Med Hyg 57(2) (1997), 180-186.

[29] Heтнсоте, H. The Mathematic of Infectious Disease, vol. 42. SIAM Review, 2000.

[30] Hirsch, M. W., And Smale, S. Differential Equations, Dynamical Systems and An Introduction to Chaos, second edition ed. Academic Press, 2004.

[31] Ingraham, J., And Ingraham, C. Introducción a la Microbiología, vol. 2. Reverté, 1998.

[32] Jitender P. Dubey. A review of toxoplasmosis in cattle. J. Vet Parasitol 22(3-4) (1986), 177-202.

[33] Jitender P. Dubey. A review of toxoplasmosis in pigs. J. Vet Parasitol 19(3-4) (1986), 181-223.

[34] Jitender P. Dubey. Toxoplasmosis of animals and man. CRC Press, 1988.

[35] Jitender P. Dubey. Duration of immunity to shedding of toxoplasma gondii oocysts by cats. J. Parasitol 81(3), 3 (1995), 410-415.

[36] Jitender P. Dubey. Toxoplasmosis of Animals and Humans, second ed. CRC Press, 2009.

[37] Jitender P. Dubey, Bowie, J., Renton, I., King, W. R., Irwin, S., Ong, C., Fung, C. P., And Shokeir, O. Detection of toxoplasma gondii oocysts in drinking water. J. Appl Environ Microbiol 64(6) (1998), 2278-2280. 
[38] Jitender P. Dubey, Frenkel, J. K., and Miller, N. L. Toxoplasma gondii in cats: fecal stages identified as coccidian oocysts. J. Science 167(3919) (1970), 893-896.

[39] Jitender P. Dubey, Lindsay, D. S., And Speer, C. A. Structures of toxoplasma gondii tachyzoites, bradyzoites, and sporozoites and biology and development of tissue cysts. J. Clinical Microbiol 11 (1998), 267-299.

[40] Jones, J., Lopez, A., And Wilson, M. Congenital toxoplasmosis. a review. Obstet Gynecol Surv 56(5) (2001), 296-305.

[41] Kravetz, J., And Federman, D. Toxoplasmosis in pregnancy. Amer J Med 118(3), 3 (2004), 212-216.

[42] Martínez, D., Martnez, E., Oberto, L., and Navas, P. Seroprevalencia de la toxoplasmosis en mujeres que asistieron hospital "dr. rafael gallardo". coro, estado facón. Socie Venez Microb 29 (2009), 49-51.

[43] Mateus-Pinilla, N. E., Hannon, B., And Weigel, R. M. A computer simulation of the prevention of the transmission of toxoplasma gondii on swine farms using a feline t. gondii vaccine. J. Prev Vet Med 55, 1 (2002), 17-36.

[44] Mena-Lorca, J., And Hethcote, H. Dynamic model of infectious diseases as regulators of population size. J. Math Biol 30 (1992), 693-716.

[45] Ministerio-Protección-Social. Estadísticas, mortalidad infantil república de colombia. http://www.minproteccionsocial.gov.co/estadisticas/default.aspx, Sept 2007.

[46] Murray, J. D. Mathematical Biology I. An Introduction, third edition ed. Springer, 2001.

[47] Oliveira, G., Oliveira, S., Araujo, J. P., and Amarante, T. Pcr-based detection of babesia bovis and babesia bigemina in their natural host boophilus microplus and cattle. International J. for parasitology 35 (2005), 105-111.

[48] Pineda-Granados, F., Valero, V., and Agudelo, C. Evaluación del programa de control de la malaria en la amazonía colombiana. Rev. Salud Pública 6 (2004), $40-49$.

[49] Quiroz, H. Parasitología y enfermedades parasitarias de animales domésticos, first ed. Limusa, 2002.

[50] Reyes-lizano, L., Chinchilla-Carmona, M., Guerrero-Bermúdez, O., Arias-Echandi, M., and Castro-Castillo, A. Transmisión del toxoplasma 
gondii en costa rica: Un concepto actualizado. Acta Médica Costarric 43(1), 1 (2001), 36-38.

[51] Rodríguez-Morales, A. Epidemiología de la babesiosis: Zoonosis emergente. $I C$ Journals 5(4) (2007), 132-138.

[52] Rosso, D., And Mahoney, D. Epizootiological factors in the control of bovine babesiosis. Austr Vet J 48(5) (1972), 292-298.

[53] Rosso, F., Agudelo, A., And Montoya, J. Toxoplasmosis congénita: aspectos clnicos y epidemiológicos de la infección durante el embarazo. Colomb Med 38 (2007), 316-337.

[54] Rosso, F., Les, J., Agudelo, A., Villalobos, C., Chavez, J., Tunubala, G., Messa, A., Remington, J., And Montoya, J. Prevalence of infection with toxoplasma gondii among pregnant women in cali, colombia south america. $J$. Tropical Medicine and Hygiene 78, 3 (2008), 504-508.

[55] SÁnchez, C. Una mirada a las enfermedades parasitarias en el país. NOVA 4 (2006), 1-116.

[56] Seuc, A., Domínguez, E., Gallardo, U., García, R., López, L., And OCHOA, E. G. Mortalidad y años de vida potencial perdidos por muertes prematuras en mujeres cubanas: 1990, 1995 y 2000. Rev Cubana Salud Pública 30(4) (2004).

[57] Shall, J., Pearson, A., And Perkins, S. Prevalence of malaria parasites (plasmodium floridense and plasmodium azurophilum) infecting a puerto rican lizard (anolis gundlanchi): Nine year study. J. Parasitology 86, 3 (2000), 511-515.

[58] Sibley, D., And Boothroyd. Letters nature, in: Department of molecular microbiology. University School of MedicineWashington 359 (1992), 82-85.

[59] Sibley, D., And Boothroyd. Virulent strains of toxoplasma gondii comprise a single clonal lineage. J. Nature 359 (1992), 410-415.

[60] Simon, C., ANd Jacquez, J. Reproduction numbers and the stability of equilibria of si models for heterogeneous populations. SIAM J. Appl. Math 52(2) (1992), 541576.

[61] Smith, H., Kaminsky, R., Niwas, R., Soto, R., And Jolly, P. Prevalence and intensity of infections of ascaris lumbricoides and trichuris trichiura and associated socio-demographic variables in four rural honduran communities. Mem Inst Oswaldo Cruz 96 (2001), 14-303. 
[62] Solorio-Rivera, J., And Rodríguez-Vivas, R. Epidemiologa de la babesiosis bovina. ii. indicadores epidemiolgicos y elementos para el diseo de estrategias de control. J. Biomed 8 (1997), 95-105.

[63] Solorio-Rivera, J., And Rodríguez-Vivas, R. Epidemiología de la babesiosis bovina. i. componentes epidemiológicos. J. Biomed 8 (1997), 37-47.

[64] Solorio-Rivera, J., And Rodríguez-Vivas, R. Epidemiología de la babesiosis bovina. ii. indicadores epidemiológicos y elementos para el diseño de estrategias de control. J. Biomed 8 (1997), 95-105.

[65] Sunquist, M., And Sunquist, F. Wild Cats of the World. The University of Chicago Press, Chicago and London, 2002.

[66] TANG, Y., AND LI, W. Global dynamics of an epidemic model with an unspecified degree. J. Comp Math Appli 53, 11 (2007), 1704-1717.

[67] Thieme, H. Mathematics in population biology. Princeton University Press, 2003.

[68] Uribe, O., Arias, H., and Catellanos. Prevalencia de varias entidades patológicas en bovinos del magdalena medio (colombia). Rev. ICA (Colombia) 25(3) (1990), 185-191.

[69] VÁzquez-Marquez, J. I meeting of the inter-american commission of animal health. IICA 5 (1983), 323-360.

[70] World-Health-Organization. La tenencia responsable es la mejor receta para el bienestar del animal y la salud del amo. http://www.paho.org/spanish/dd/pin/Numero21_articulo05.htm, Sep 2008. 